\title{
Union Carbide Ethylene Polymerization Catalyst: From Uncovering Active Site Structures to Designing Molecularly-Defined Analogs
}

\author{
David Trummer, ${ }^{\ddagger, \S}$ Anna G. Nobile, ${ }^{\ddagger, \S}$ Pierre-Adrien Payard, ${ }^{\ddagger, \S}$ Anton Ashuiev, ${ }^{\ddagger}$ Yuya Kakiuchi, ${ }^{\ddagger}$ Daniel Klose, ${ }^{\ddagger}$ \\ Gunnar Jeschke, ${ }^{\ddagger *}$ Christophe Copéret ${ }^{\ddagger * *}$ \\ ‡ Department of Chemistry and Applied Biosciences, ETH Zürich, Vladimir-Prelog-Weg 2, CH-8093 Zürich, \\ Switzerland, \\ E-mail: ccoperet@ethz.ch; gunnar.jeschke@phys.chem.ethz.ch
}

\begin{abstract}
The Union Carbide(UC) catalyst, one of the first ethylene polymerization (EP) catalysts based on supported organometallic compounds, is based on chromocene dispersed on silica; it is distinct from the corresponding Phillips catalysts, based on supported chromium oxide, because it is responsive to $\mathrm{H}_{2}$ enabling tuning the resulting polymer. Yet, despite 50 years of research, the structure of its active sites has also been controversially discussed and remains elusive. Based on a combination of IR, EPR spectroscopies, labeling experiments, and modeling at the DFT level, we identified monomeric surface-supported $\mathrm{Cr}$ (III) hydrides, $(\equiv \mathrm{SiO}) \mathrm{Cr}(\mathrm{Cp})-\mathrm{H}$, as the active sites of the UC catalyst. These active sites, with distinct EPR signatures, are exclusively formed at high $\mathrm{Cr}$ loadings because their formation requires a combination of congruent factors, namely the presence of grafted as well as adsorbed chromocene together with residual surface $\mathrm{OH}$ groups, and involves a C$\mathrm{H}$ bond activation step of the $\mathrm{Cp}$ ring. These $\mathrm{Cr}$-hydrides readily initiate polymerization, yielding $\mathrm{Cr}$ (III) alkyl species that insert ethylene monomers through a Cossee-Arlman-type mechanism, as evidenced by labeling and spectroscopic studies. This information inspired the design of a well-defined analog, that was prepared and characterized using SOMC by grafting $\mathrm{CpCr}\left(\mathrm{CH}\left(\mathrm{SiMe}_{3}\right)_{2}\right)_{2}$ on partially dehydroxylated silica. The resulting surface $\mathrm{Cr}$ sites show similar EPR signatures and produce similar polyethylene as the UC catalyst, further supporting the presence of similar active sites and opening the way to generating new classes of catalysts.
\end{abstract}




\section{INTRODUCTION}

Nowadays, polyethylene is one of the most commonly used plastics worldwide, with high-density polyethylene (HDPE) accounting for the largest proportion of ca. $45 \% .{ }^{1}$ At the present time, Ziegler-Natta catalysts account for roughly $60 \%$ of the annual world production of polyethylene. The silica-supported chromium oxide Phillips catalyst represents the other $40 \%$ of worldwide production. ${ }^{1} \mathrm{An}$ alternative $\mathrm{Cr}$-based catalyst was developed by the Union Carbide Corporation (UC) in the early 1970's based on silica-supported chromocene, $\left[\mathrm{Cp}_{2} \mathrm{Cr}(\mathrm{II})\right](\mathbf{1}) .^{2-4}$ This catalyst is obtained by contacting a solution of $\mathbf{1}$ with partially dehydroxylated silica. The UC catalyst probably corresponds to one of the first industrially applied heterogeneous catalysts prepared from an organometallic reagent supported on silica, thus pioneering the field of surface organometallic chemistry (SOMC). ${ }^{5,6}$ Compared to the Phillips catalyst, the UC catalyst is more active towards ethylene polymerization and requires lower reaction temperatures. Furthermore, its high response to dihydrogen allows for chain length control by $\mathrm{H}_{2}$ addition. ${ }^{4,}$ 7-10 The generally narrower molecular weight distribution (MWD) of the polyethylene produced by the UC catalyst compared to the Phillips catalyst makes the UC system an attractive alternative EP catalyst, although its lower temperature resistance has limited its applicability.

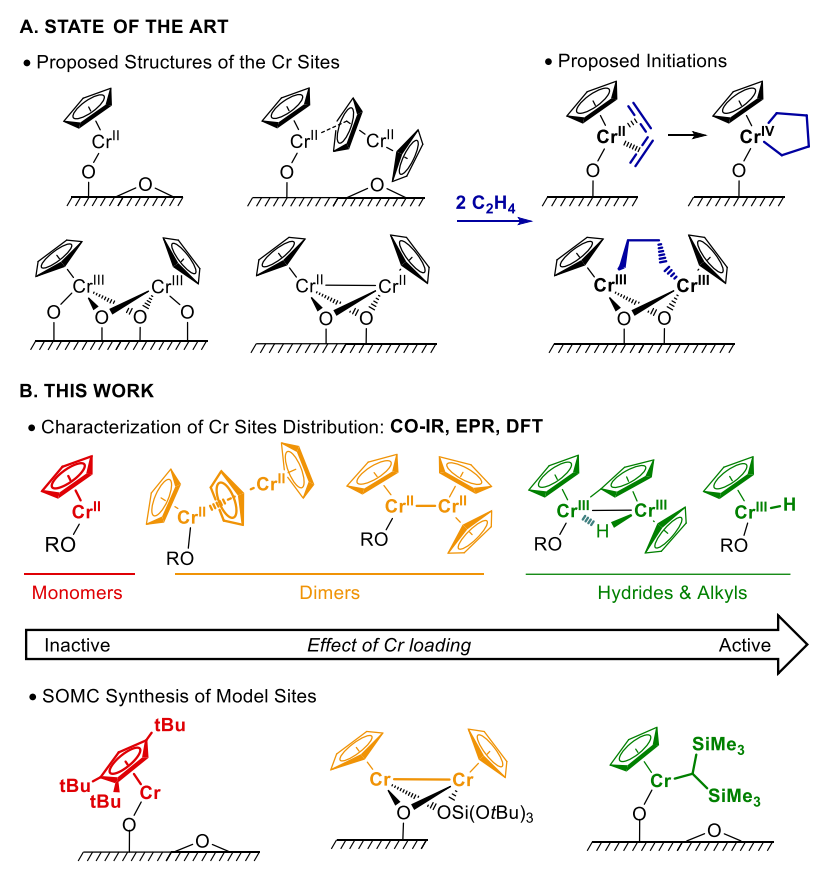

Figure 1. A) Previously proposed surface and active sites structures of the UC catalyst. B) Illustration of $\mathrm{Cr}$ sites (above the arrow) investigated by CO-IR, EPR, and DFT modeling as a function of the $\mathrm{Cr}$ loading in agreement with experimental results. Monomeric (in red) and dimeric (in orange) $\mathrm{Cr}(\mathrm{II})$ sites show no activity while monomeric $\mathrm{Cr}$ (III) sites (in green) are active in EP. The respective well-defined monomeric and dimeric $\mathrm{Cr}(\mathrm{II})$, as well as monomeric alkyl-Cr(III) sites, (below the arrow) are designed using the SOMC approach.

Despite decades of research, the nature of the active site of the UC catalyst, as well as its operating mechanism, are still debated (Fig. 1A). Indeed, the diversity of surface sites, together with the low number of active ones compared to the overall amount of chromium (few \%), have made the elucidation of the active site structure and mechanistic investigations challenging. ${ }^{9}$

Notably, the density of hydroxyl groups on the silica surface has a decisive influence on the polymerization activity, that increases with decreasing surface-OH density. ${ }^{11} \mathrm{~A}$ variety of $\mathrm{Cr}$ sites has been previously observed after reacting dehydroxylated silica with $\mathbf{1}$. Based on IR and UV-vis investigations, the formation of mono-grafted 1, i.e. ( $\equiv \mathrm{SiO}) \mathrm{CrCp}$, together with chemisorbed 1 (i.e. $\mathrm{Cp}_{2} \mathrm{Cr}^{\cdots} \mathrm{SiO}_{2}$ ) at higher $\mathrm{Cr}$ loadings (see Fig. $1 \mathrm{~A}$ ), was proposed. ${ }^{4}$ 7,12 This monomeric site has been suggested to generate the corresponding monomeric $\mathrm{Cr}$ (IV) metallacycle (Fig. 
$1 \mathrm{~A}$, right) in the presence of ethylene. ${ }^{13}$ The formation of $\mathrm{Cr}$-dimers was also reported. Schnellbach et al. identified predominantly dimeric half sandwich $\mathrm{Cr}(\mathrm{II})$ sites on silica (Fig. 1A), based on ${ }^{1} \mathrm{H}$ MAS NMR investigations. ${ }^{8}$ The latter would react with ethylene to yield dimeric $\mathrm{Cr}$ (III) alkyl silicates (Fig. $1 \mathrm{~A}$, right). ${ }^{13}$ However, X-ray absorption studies provided evidence for dimeric silica-supported $\mathrm{Cr}(\mathrm{III})$ species $\mathrm{Cp}_{2} \mathrm{Cr}_{2} \mathrm{O}_{4}$ before ethylene treatment (Fig. 1A). ${ }^{14}$

Investigations on potential model systems for the UC catalyst using lanthanide(II)-analogs of $\mathbf{1}$ showed that silicasupported $\mathrm{Sm}(\mathrm{II})$ and $\mathrm{Yb}(\mathrm{II})$ cyclopentadienyls, polymerize ethylene, probably initiated via single electron transfer (SET) activation without the need of alkylating co-catalysts. ${ }^{15}$ However, the significantly lower oxidation potential of chromocene (1) compared to $\mathrm{Cp}^{*}{ }_{2} \mathrm{Ln}(\mathrm{Ln}=\mathrm{Sm}(\mathrm{II})$ and $\mathrm{Yb}(\mathrm{II}))$ complexes makes a comparable activation step in the UC catalyst unlikely. Furthermore, the silica-supported $\mathrm{Cp}_{2}{ }_{2} \mathrm{Ln}$ catalysts typically produce polyethylene with a narrower MWD than the UC system, thus indicating a different type of active sites for the UC catalyst. ${ }^{2 c, 9}$

In this work (Fig. 1B), we selectively prepare and characterize various $\mathrm{Cr}$ surface sites present in the UC catalyst, using SOMC together with detailed combined spectroscopic and computational studies. In Part 1, using $\mathrm{CO}$ as a probe molecule for IR investigations, we identify various surface $\mathrm{Cr}$ sites of the UC system as a function of $\mathrm{Cr}$ loadings on dehydroxylated silica. We support our assignments by comparison of spectroscopic responses from industrial-like catalysts with those of well-defined model systems, prepared via SOMC. Using this approach, we evidence the presence of surface $\mathrm{Cr}$ hydrides in the UC catalysts at high loading (Part 1). The presence of these $\mathrm{Cr}$ (III) hydrides is further confirmed by EPR spectroscopy. In Part 2, we investigate possible pathways for $\mathrm{Cr}$ hydrides formation using ${ }^{2} \mathrm{H}$ labeling and DFT calculations. The $\mathrm{CO}$ vibrational frequencies of the proposed sites were further calculated at the DFT level and compared with the experimental ones described in Part 1 to further validate the assignments. Overall, we propose that two $\mathrm{Cr}$ moieties, one grafted and the other one adsorbed, are cooperating to generate supported monomeric and dimeric $\mathrm{Cr}(\mathrm{III})$ hydrides involving a $\mathrm{C}-\mathrm{H}$ activation of the $\mathrm{Cp}$ ring. In Part 3, using DFT calculations, we show that monomeric $\mathrm{Cr}$ (III) hydrides initiate ethylene polymerization via $\mathrm{C}_{2} \mathrm{H}_{4}$ insertion into the $\mathrm{Cr}(\mathrm{III})-\mathrm{H}$ bond with the subsequent formation of $\mathrm{Cr}(\mathrm{III})$ alkyl species ( $\left.\equiv \mathrm{SiO}\right) \mathrm{Cr}(\mathrm{Cp})-\mathrm{R}(\mathrm{R}=$ $\left.\mathrm{C}_{2} \mathrm{H}_{5},-\left(\mathrm{CH}_{2}\right)_{n}-\mathrm{CH}_{3}\right)$ that enable further insertion and polymer formation. Finally, in Part 4, we develop a molecularly-defined analog of the active sites - namely $(\equiv \mathrm{SiO}) \mathrm{CrCp}\left[\mathrm{CH}\left(\mathrm{SiMe}_{3}\right)_{2}\right]$ - by grafting a tailored molecular precursor. This well-defined $\mathrm{Cr}(\mathrm{III})$-alkyl initiates ethylene polymerization, as evidenced by EPR hyperfine spectroscopy using ${ }^{2} \mathrm{H}$-labeling strategies. Overall, this study show that the active sites of the UC catalyst correspond to surface $\mathrm{Cr}(\mathrm{III})$ hydrides/alkyls and that it is possible to generate well-defined analogs. 


\section{Results and Discussions}

\section{Characterization of monomeric $\mathrm{Cr}(I I I)$ hydrides by CO-IR probe and EPR spectroscopies}

The direct observation of the active site of the UC catalyst is challenging because of the simultaneous presence of various $\mathrm{Cr}$ surface species and the small amounts of active sites in this system. Nevertheless, the identification of the active sites could be possible if one detects a spectroscopic signature that changes under reaction conditions or that correlates with the polymerization activity. ${ }^{10}$

As reported earlier, ${ }^{2-4}$ the EP activity of the UC catalyst is critically dependent on the $\mathrm{Cr}$ loading. Therefore, four different $\mathrm{Cr}$ loadings were investigated by contacting varying amounts of $\mathbf{1}$ with silica, partially dehydroxylated at $700{ }^{\circ} \mathrm{C}\left(\mathrm{SiO}_{2-700}\right.$, see $\mathrm{SI}$, Section 1 ) that contains mostly isolated surface $\mathrm{OH}$ groups. ${ }^{11}$ Contacting of 1 with $\mathrm{SiO}_{2-700}$ led in all cases to an instant color change of the white silica powder to dark blue/black and a decrease in of the IR

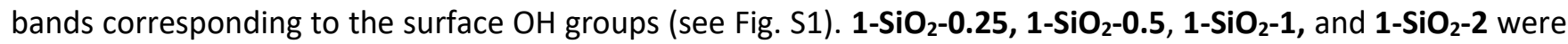
obtained using $0.25,0.5,1.0$, and 2.0 wt. \% of $\mathrm{Cr}$, respectively (see SI, Section 2.1 for preparation details ). According to elemental analysis and ${ }^{1} \mathrm{H}$ NMR quantifications of the washing solutions (see SI, Section 2.1 \& Table $\mathrm{S} 1$ ), about one $\mathrm{Cp} / \mathrm{Cr}$ is present on silica for $1-\mathrm{SiO}_{2}-\mathbf{0 . 2 5}$, suggesting the presence of exclusively mono-grafted sites. However, with increasing $\mathrm{Cr}$ loadings, the $\mathrm{Cp} / \mathrm{Cr}$ ratio increases, reaching an almost $3 \mathrm{Cp} / 2 \mathrm{Cr}$ ratio in 1-SiO1. These findings suggest the presence of both grafted and strongly adsorbed (possibly chemisorbed) 1 on silica at higher $\mathrm{Cr}$ loadings. The EP activities for all the obtained materials show the following trends: while 1-SiO $\mathbf{O}_{2}-\mathbf{1}$ and

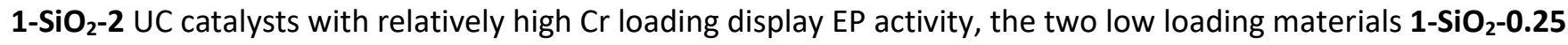
and $\mathbf{1}-\mathrm{SiO}_{2}-\mathbf{0 . 5}$ show hardly any activity (see Table S2). Therefore, high $\mathrm{Cr}$ loadings ( $>1.0 \mathrm{wt}$. \% of $\mathrm{Cr}$ ) are required to generate the active sites in UC catalyst, as discussed earlier.

In order to characterize the $\mathrm{Cr}$ species in the UC system, including the active site structure, we performed IR spectroscopic studies of the prepared UC catalysts with different $\mathrm{Cr}$ loadings (Fig. 2). We used CO gas as a probe molecule ${ }^{6}$ for the identification of the various $\mathrm{Cr}$ surface sites that display different IR vibrational frequencies of the adsorbed CO molecules (CO-IR probe; see SI Section 1). The various $\mathrm{Cr}$ sites were then assigned by a comparison of their IR frequencies with those of the well-defined $\mathrm{Cr}$ surface species prepared by SOMC (see also Fig. $1 \mathrm{~B}$ and Fig. 2, 2-SiO ${ }_{2}$ and 3-SiO${ }_{2}$ ) and DFT calculations on model systems (see Part 2). Since the EP activity of the UC system was observed only at high $\mathrm{Cr}$ loadings ( $\geq 1 \mathrm{wt}$. \%, 1-SiO $\mathbf{2}-\mathbf{1}$ and $\mathbf{1 - S i O _ { 2 } - 2}$ ), the CO-IR signature of the active sites may be assessed by comparison with the CO-IR response at low $\mathrm{Cr}$ loading samples (1-SiO $\mathbf{2}_{2}-\mathbf{0 . 2 5}$ and 1-SiO $2-0.5$ ), inactive in EP. 


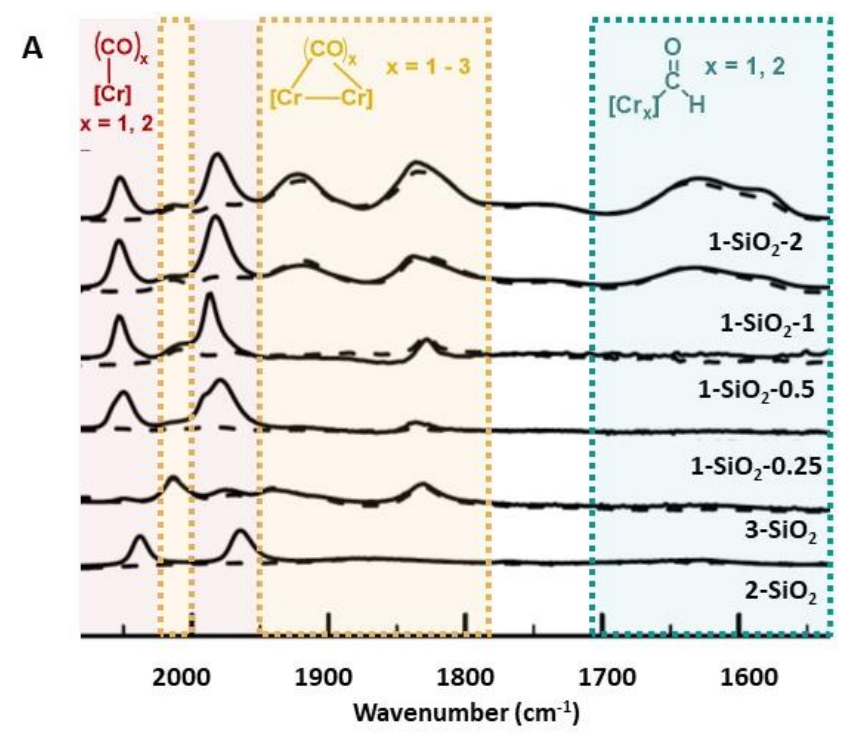

B
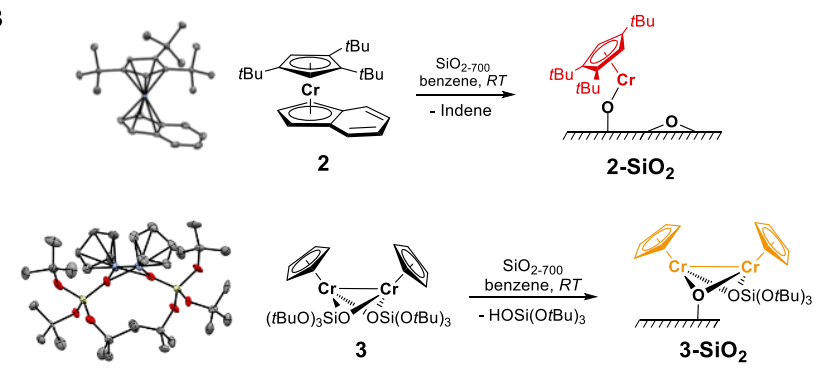

Figure 2. A) Background-subtracted IR spectra (solid lines) of the UC catalysts $\mathbf{1}-\mathrm{SiO}_{2}-\mathbf{0 . 2 5}, \mathbf{1}-\mathrm{SiO}_{2}-\mathbf{0 . 5}, \mathbf{1}-\mathrm{SiO}_{2}-\mathbf{1}$, and 1-SiO $\mathbf{S}_{2}-\mathbf{2}$ after exposure to $\mathrm{CO}\left(25 \mathrm{mbar}\right.$ ), as well as of model systems $\mathbf{2}-\mathbf{S i O}_{\mathbf{2}}$ and $\mathbf{3}-\mathbf{S i O}_{\mathbf{2}}$ (see Fig. 2B). Dashed lines indicate the IR spectra after the exposure of the corresponding CO-adsorbed materials to high vacuum $\left(10^{-5}\right.$ mbar). CO bands that disappear under vacuum are marked in red (indicative of monomeric $\mathrm{Cr}(\mathrm{II})$ sites). Bands from irreversibly bound CO molecules are marked in orange (indicative of bridging $\mathrm{CO}$ between interacting $\mathrm{Cr}$ atoms). Low energy $\mathrm{CO}$ bands are marked in green (indicative of formyl groups that correlate with the EP activity in the high $\mathrm{Cr}$ loading silica materials). B) Grafting of tailored monomeric and dimeric model complexes on $\mathrm{SiO}_{2-}$ 700. Both the monomeric (2-SiO 2$)$ and dimeric $\left(\mathbf{3}-\mathrm{SiO}_{2}\right)$ model systems show no activity in EP.

As shown in Fig. 2A, the IR spectrum of the EP-active catalyst, 1-SiO $\mathbf{2}_{\mathbf{2}} \mathbf{- 1}$ after $\mathrm{CO}$ adsorption, displays a high level of complexity with a variety of different $\mathrm{CO}$ bands spreading over a large range of wavenumbers $\left(2100-1500 \mathrm{~cm}^{-}\right.$ $\left.{ }^{1}\right)$. In contrast, the low-loading material $\mathbf{1}-\mathrm{SiO}_{2}-\mathbf{0 . 2 5}$ after exposition to $\mathrm{CO}$ shows only two predominant $\mathrm{CO}$ bands at $2061 \mathrm{~cm}^{-1}$ and $1981 \mathrm{~cm}^{-1}$; these bands are also observed in all the other materials (Fig. 2A, red region). We observed that these bands disappear upon exposure of the materials to high vacuum $\left(10^{-5} \mathrm{mbar}\right.$; see Fig. $2 \mathrm{~A}$, dashed lines). This indicates the reversible and weak binding of $\mathrm{CO}$ to these $\mathrm{Cr}$ surface sites.

With increasing the $\mathrm{Cr}$ loading to $0.5 \mathrm{wt}$. \% (1-SiO ${ }_{2}-\mathbf{0 . 5}$ ), three additional bands at $2015 \mathrm{~cm}^{-1}, \sim 1905 \mathrm{~cm}^{-1}$ (broad) and $1837 \mathrm{~cm}^{-1}$ arise (Fig. 2A, orange region). In contrast to the previously observed bands (Fig. 2A, red region), these IR signals do not disappear upon exposure to high vacuum. This indicates an irreversible (stronger) binding of $\mathrm{CO}$ molecules to these additional $\mathrm{Cr}$ sites. Upon further increasing the $\mathrm{Cr}$ content to $1 \mathrm{wt}$. \% $\left(\mathbf{1}-\mathrm{SiO}_{\mathbf{2}}-\mathbf{1}\right)$, three additional rather broad CO bands appear at $1742 \mathrm{~cm}^{-1}, 1630 \mathrm{~cm}^{-1}$, and $1579 \mathrm{~cm}^{-1}$ (Fig. 2A, green region).

A further increase in the $\mathrm{Cr}$ loading on silica (2 wt. \% $\mathrm{Cr}$, 1-SiO ${ }_{2}-\mathbf{2}$ ) does not lead to the appearance of new $\mathrm{CO}$ adsorption bands in the corresponding IR spectrum, though the peak at $1579 \mathrm{~cm}^{-1}$ gains in intensity (see Fig. 2A). 
Note that the appearance of such bands (Fig. 2A, green region) correlates with the EP activity of 1-SiO $\mathbf{2}_{\mathbf{2}} \mathbf{- 1}$ and $\mathbf{1 -}$

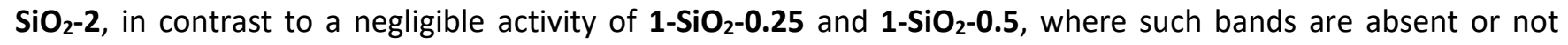
observed (very low intensity). This finding suggests that there is a relation between these bands and the active site(s) in the UC catalyst.

We then focused on the assignment of the CO-IR bands observed in the three groups in Fig. 2A. As said, the two bands at $2061 \mathrm{~cm}^{-1}$ and $1981 \mathrm{~cm}^{-1}$, together with a small shoulder at $1993 \mathrm{~cm}^{-1}$, which are related to reversibly bound $\mathrm{CO}$ molecules (Fig. 2A, red), are the only $\mathrm{CO}$ bands observed for the UC catalyst $\mathbf{1}-\mathrm{SiO}_{2}-\mathbf{0 . 2 5}$ with low $\mathrm{Cr}$ loading. We hypothesized that they could therefore be assigned to monomeric $\mathrm{Cr}$ surface sites. In order to verify this hypothesis, we developed a well-defined silica-supported monomeric $\mathrm{Cr}(\mathrm{II})$ species, originating from the

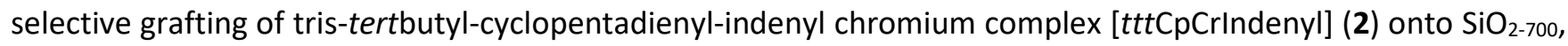
as shown in Fig. 2B. Complex $\mathbf{2}$ is, in fact, the first example of a $\mathrm{Cr}$-based metallocene complex with two different types of $\mathrm{Cp}$ ligands, while similar metallocene complexes were described for $\mathrm{Mn}, \mathrm{Co}$, and $\mathrm{Ni}^{16,17}$ (see $\mathrm{SI}$ Section $\mathbf{2 . 2}$ for the details of the synthesis of $\mathbf{2}$ and Fig. S2 for its crystal structure). This molecular model system reacts quantitatively with hydroxyl groups on $\mathrm{SiO}_{2-700}$ to produce well-defined monomeric $(\equiv \mathrm{SiO}) \mathrm{Cr}(t t \mathrm{Cp})$ sites $\left(\mathbf{2}-\mathbf{S i O}_{2}\right.$, Fig. 2B). A stoichiometric amount of indene is released in the washing solution, as verified by ${ }^{1} \mathrm{H} N M R$ quantification (see SI Section 2.2, and Fig. S3 for the IR spectra). The structure of the monomeric $\mathrm{Cr}$ (II) site was further confirmed by X-ray absorption near-edge structure (XANES) analysis (see Fig. S4). This is in sharp contrast to most $\mathrm{Cr}$-cyclopentadienyl compounds and shows that the combination of the reactive indenyl ligand and the sterically demanding $t t t C p$ ligand favors the formation of $\mathrm{Cr}$ monomeric sites on the silica surface.

The obtained material 2-SiO 2 shows two bands at $2035 \mathrm{~cm}^{-1}$ and $1960 \mathrm{~cm}^{-1}$ upon exposition to CO (Fig. 2A). These

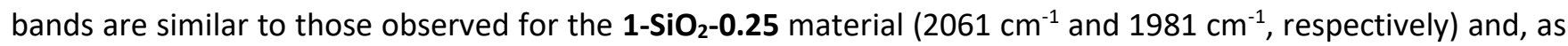
observed for $\mathbf{1}-\mathrm{SiO}_{2}-\mathbf{0 . 2 5}$, these bands disappear under vacuum. Therefore, we assign the signals between 2060 and $1950 \mathrm{~cm}^{-1}$ (red region) to CO molecules, adsorbed on monomeric $\mathrm{Cr}$ (II) sites. These two bands are respectively assigned to the symmetric and antisymmetric stretching modes of two $\mathrm{CO}$ molecules adsorbed on mono-grafted $\mathrm{Cr}$ sites, i.e. $(\equiv \mathrm{SiO}) \mathrm{CrCp}(\mathrm{CO})_{2}$, as previously suggested and confirmed by carrying out the experiment with a $1 / 1$ mixture of ${ }^{12} \mathrm{CO} /{ }^{13} \mathrm{CO} ;{ }^{6}$ (see Fig. S5). ${ }^{6}$ The small shoulder at $1993 \mathrm{~cm}^{-1}$ in $\mathbf{1 - S i O} \mathbf{2}_{2}-\mathbf{0 . 2 5}$, which also disappeared after exposure to vacuum, is attributed to a mono-carbonyl species ( $\equiv \mathrm{SiO}) \mathrm{CrCp}(\mathrm{CO})$, where the $\mathrm{Cr}$ center most likely interacts with additional Si-O-Si bridges from the silica surface.

The well-defined $\mathrm{Cr}(\mathrm{II})$ monomeric species present in $\mathbf{2}-\mathrm{SiO}_{2}$ showed no EP activity at 10 bars and $40^{\circ} \mathrm{C}$, in contrast to $1-\mathrm{SiO}_{2}-\mathbf{1}$ that rapidly polymerizes ethylene at equivalent $\mathrm{Cr}$ loading. This finding indicates that monomeric $\mathrm{Cr}$ (II) sites are not capable of polymerizing ethylene, in sharp contrast to the corresponding Sm and Yb derivatives. ${ }^{15}$

We further turned to the assignment of IR bands of the irreversibly bound CO molecules, which arise upon

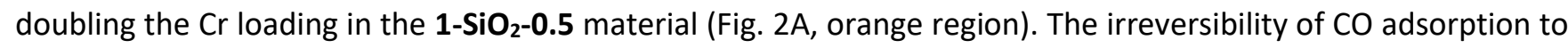
these sites could be due to the formation of a bridging $\mathrm{CO}$ between two $\mathrm{Cr}$ centers. Thus, these signals would be characteristic of dimeric $\mathrm{Cr}$ surface sites.

To confirm this interpretation, we developed the dimeric molecular model complex $\left[\mathrm{Cr}_{2} \mathrm{Cp}_{2}\left(\mathrm{OSi}(\mathrm{OtBu})_{3}\right)_{2}\right](3$, see Fig. 2B) for grafting onto silica to account for well-defined dimeric $\mathrm{Cr}(\mathrm{II})$ surface sites $3-\mathrm{SiO}_{2}$ (Fig. 2B). The winered precursor complex 3 was obtained by reacting $[\mathrm{CpCr}(\mathrm{OtBu})]_{2}$ with tris-tert-butoxy-silanol $\mathrm{HOSi}(\mathrm{OtBu})_{3 .}{ }^{18} \mathrm{Note}$ that the reaction of $\mathbf{1}$ with $\mathrm{HOSi}(\mathrm{OtBu})_{3}$ in toluene does not lead to the formation of $\mathbf{3}$ (see SI Section 2.3 for details \& Fig. $\mathrm{S} 6$ for ${ }^{1} \mathrm{H}$ NMR investigations of 3). Both complexes [ $\left.\mathrm{CpCrOtBu}\right]_{2}$ and $\mathbf{3}$ show comparable short $\mathrm{Cr}$ - $\mathrm{Cr}$ bonds, although the interatomic distance in 3 is slightly shorter $(2.58 \AA)$ compared to [( $\left.\mathrm{CpCrOtBu})_{2}\right](2.65 \AA)$, which is attributed to the slightly lower steric hindrance of $\mathrm{HOSi}(\mathrm{OtBu})_{3}$ (see Fig. $\mathrm{S7}$ for the crystal structure of 3 ).

When exposed to $\mathrm{CO}, 3-\mathrm{SiO}_{2}$ shows four bands at $2012 \mathrm{~cm}^{-1}$, $1937 \mathrm{~cm}^{-1}$ (broad, including the shoulder at 1907 $\mathrm{cm}^{-1}$ ), and $1830 \mathrm{~cm}^{-1}$ resulting from irreversibly bound CO molecules (see Fig. S8 for the IR spectrum of 3-SiO 


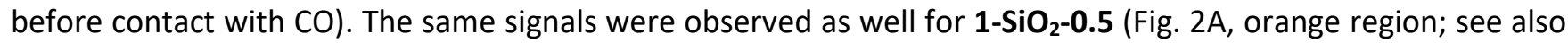
Fig. S9). The presence of at least four signals indicates that dimeric sites can adsorb either two or three CO molecules (see also SI Section 3.2 for details). These IR frequencies are consistent with the CO bands observed in 1-SiO ${ }_{2}-\mathbf{0 . 5}$ that mainly consists of two types of $\mathrm{CO}$ vibrations, as demonstrated for $\mathbf{3}-\mathrm{SiO}_{2}$. Therefore, we attribute these IR bands (Fig. 2A, orange region) to the dimeric $\mathrm{Cr}$ (II) sites of the UC system. The two additional weak bands for $3-S^{-} O_{2}$ at $2049 \mathrm{~cm}^{-1}$ and $1975 \mathrm{~cm}^{-1}$ in the red region of SFigure 2 are indicative of additional monomeric sites (vide infra).

The well-defined dimeric model system $\mathbf{3}-\mathrm{SiO}_{2}$ shows no EP activity, similar to 2-SiO $\mathbf{S}_{2}$. The absence of EP activity of $\mathbf{2}-\mathrm{SiO}_{2}$ and $\mathbf{3}-\mathrm{SiO}_{2}$ indicates that the active sites of the $\mathrm{UC}$ catalyst do not correspond to monomeric or dimeric $\mathrm{Cr}$ (II) species, in contrast to some of the previous propositions (see Fig. 1A). ${ }^{13}$ This encouraged us to further investigate the surface species associated with the low energy CO bands (Fig. 2A, green region), which become significant only for the $\mathbf{1 - S ^ { - } O _ { 2 } - 1}$ and $\mathbf{1 - S i O} \mathbf{2}_{2}-\mathbf{2}$ materials (see also Figs. S10 \& S11). The CO vibrational frequencies down to $1550 \mathrm{~cm}^{-1}$ (see Fig. 2A, green region) suggest the presence of formyl groups attached to $\mathrm{Cr}^{14} \mathrm{Their}^{1}$ formation would most likely involve the insertion of $\mathrm{CO}$ molecules into a $\mathrm{Cr}-\mathrm{H}$ bond, thus inferring the presence of $\mathrm{Cr}$ hydrides upon chemisorption of $\mathbf{1}$ at higher loadings. Such a reaction would parallel what is observed upon the reaction of $\left[\mathrm{Cp} * \mathrm{Cr}\left(\mathrm{PR}_{3}\right)(\mathrm{CO})_{3}\right]$ with a hydride source $\left(\mathrm{NaBH}_{4}\right)$ that yields $\left[\mathrm{Cp}{ }^{*} \mathrm{Cr}\left(\mathrm{PR}_{3}\right)(\mathrm{CO})_{2} \mathrm{CHO}\right]{ }^{19}$ Therefore, we propose that the UC catalysts with higher $\mathrm{Cr}$ loading (1-SiO $\mathbf{2}-\mathbf{1}$ and $\mathbf{1}-\mathbf{S i O}_{2}-\mathbf{2}$ ) contain surface-supported $\mathrm{Cr}$ hydrides, which produce $\mathrm{Cr}$ formyl species upon the contact with $\mathrm{CO}$, resulting in characteristic IR bands (Fig. 2A, green region). Since these bands grow in intensity for the UC catalysts active in EP (see Fig. 2A), the proposed $\mathrm{Cr}$ hydrides could indeed be the active or initiating sites of EP, in analogy with previously described ethylene polymerizing Ti hydrides. ${ }^{15}$

In order to examine the possible presence of surface $\mathrm{Cr}$ hydrides as initiation sites of EP, we carried out IR investigations of the UC catalysts after contact with ethylene, i.e. of the catalysts together with the produced polyethylene. For these studies, we used perdeuterated ethylene $\left(C_{2} D_{4}\right)$ in order to analyze the end groups in the produced polymer chains. Exposure of $1-\mathrm{SiO}_{2}-\mathbf{1}$ to 100 mbar of $\mathrm{C}_{2} \mathrm{D}_{4}$ at room temperature revealed the appearance of two intense bands $\left(v_{C-D}=2195 \mathrm{~cm}^{-1}, 2090 \mathrm{~cm}^{-1}\right)$ consistent with the antisymmetric and symmetric stretching modes of $-\mathrm{CD}_{2}$ - groups in the main body of the polymer chain (Fig. S12A). ${ }^{16}$ At the same time, we also observed a weak band at $2887 \mathrm{~cm}^{-1}$ (see Fig. S12A), which implies the presence of $\mathrm{C}-\mathrm{H}$ vibrations, and could be tentatively assigned to the $\mathrm{C}-\mathrm{H}$ stretching vibration of the end $-\mathrm{CD}_{2} \mathrm{H}$ group. This could be further confirmed by the presence of two different types of $-\mathrm{CD}_{2}$ - symmetric and antisymmetric stretching modes (see Fig. S12A), which points towards the existence of two different types of $-C D_{2}$ - moieties in the produced polyethylene. These $-C_{2}-$ bands of low intensity, together with the weak $\mathrm{C}-\mathrm{H}$ band (Fig. S12A, green), could then be assigned to the $-\mathrm{CD}_{2} \mathrm{H}$ group, which is the expected end group of the polymer chain when assuming $\mathrm{Cr}$ hydrides as initiating sites.

Further experimental evidence for the involvement of $\mathrm{Cr}$ hydrides in the activation of ethylene was obtained from the characterization of the produced polyethylene by 2D J-mediated heteronuclear multi-quantum correlation $(\mathrm{HMQC})^{20} \mathrm{MAS} N M R$, after contacting 1-SiO -1 with ${ }^{13} \mathrm{C}_{2} \mathrm{D}_{4}$ (Fig. S12B). This NMR approach yields correlated signals from covalently bonded $\mathrm{J}$-coupled ${ }^{1} \mathrm{H}$ and ${ }^{13} \mathrm{C}$ nuclei. For this experiment, we used both ${ }^{2} \mathrm{H}$ - and ${ }^{13} \mathrm{C}$-labeled ethylene $\left({ }^{13} \mathrm{C}_{2} \mathrm{D}_{4}\right)$; therefore, the only possible proton $\left({ }^{1} \mathrm{H}\right)$ sources are the surface hydroxyl groups and the $\mathrm{Cp}$ ligands attached to $\mathrm{Cr}$. The HMQC spectrum (Fig. S12B) shows narrow and well-resolved correlations between the ${ }^{13} \mathrm{C}$ signals at 29 and $31 \mathrm{ppm}$ and the ${ }^{1} \mathrm{H}$ signal at $1.5 \mathrm{ppm}$, indicative for $-{ }^{13} \mathrm{CHD}$ - moieties in the polyethylene chain. ${ }^{21-23}$ Therefore, we unambiguously established the transfer of ${ }^{1} \mathrm{H}$ species from the UC catalysts into the polymer chain during EP, that is consistent with a hydride-mediated initiation mechanism.

The potential activity of the proposed $\mathrm{Cr}$ hydrides in EP raises questions about the oxidation state of $\mathrm{Cr}$. Being inspired by previous work, that points towards the presence of $\mathrm{Cr}(\mathrm{III})$ sites in the UC system, ${ }^{7}$ we performed EPR spectroscopic studies of the prepared UC catalysts. We found that the CW EPR spectrum of 1-SiO $\mathbf{2}_{-} \mathbf{- 1}$, active in EP, 
contains paramagnetic species even before its contact with ethylene (Fig. S13A, top). These species are most consistent with $\mathrm{Cr}$ (III) surface sites, where the major fraction is represented by a nearly axial monomeric low-spin $\mathrm{Cr}$ (III) species with $g_{\mathrm{x}}=1.9831, g_{\mathrm{y}}=2.0189, g_{\mathrm{z}}=2.0193$ (Fig. S13A, top,), together with a minor contribution of high-spin $\mathrm{Cr}$ (III). The low-spin $\mathrm{Cr}$ (III) species change their electronic properties upon contact with ethylene. As evidenced by a change in their CW EPR spectra (Fig. S13B): the $g$ tensor is better simulated as being orthorhombic $\left(g_{\mathrm{x}}=1.9900, g_{\mathrm{y}}=2.0025, g_{\mathrm{z}}=2.0184\right.$, Fig. S13A, bottom, red $)$ and the $g_{\mathrm{x}}$ value increases, consistently with a change in the ligand surrounding of the low-spin $\mathrm{Cr}$ (III) sites. Taking into account that $\mathrm{Cr}$ hydrides were identified based on CO-IR and ${ }^{1} \mathrm{H}$ MAS NMR investigations and that their presence is correlated to catalytic activity, we therefore propose that the active species are monomeric $\mathrm{Cr}(\mathrm{III})$ hydrides.

To summarize, we identified the presence of both mono- and dimeric $\mathrm{Cr}$ (II) surface sites in the UC system and showed that they are inactive in EP. At the same time, at higher $\mathrm{Cr}$ loadings the surface-supported $\mathrm{Cr}$ hydride complexes are present. The presence of these $\mathrm{Cr}$ hydride species is correlated with the EP activity of the UC catalyst. Furthermore, these hydrides were evidenced to be involved in the activation of ethylene. Together with the identified $\mathrm{Cr}$ (III) site, which changes its EPR signature upon contact with ethylene, we conclude that the active site of the UC catalyst is likely a monomeric $\mathrm{Cr}(\mathrm{III})$ hydride.

\section{Formation and further characterization of surface Cr hydrides}

After having established that most likely $\mathrm{Cr}$ (III) hydrides are involved in the activation of ethylene, we investigate possible pathways for their formation, inspired by literature and complementary labeling studies. Indeed, the formation of binuclear bridging $\mathrm{Cr}$ hydride complexes has been previously reported, ${ }^{24-27}$ while monomeric $\mathrm{Cr}$ hydrides are rather rare. ${ }^{28}$ Sinema et al. reported a $\mathrm{C}-\mathrm{H}$ activation step at the $\mathrm{Cp}$ ligand on ansa-chromocene complexes in the presence of $\left[\mathrm{H}\left(\mathrm{OEt}_{2}\right)_{2} \mathrm{BAr}_{4}\right],{ }^{29}$ and the related activation pathways were reported for other $3 \mathrm{~d}$ metallocene-based complexes. ${ }^{30,}{ }^{31}$ In analogy to $\mathrm{Cr}$, di-nuclear bridging molybdocene-hydride complexes with activated $\mathrm{Cp}$ ligands are also known. ${ }^{32}$

To investigate whether related $\mathrm{C}-\mathrm{H}$ activation of the $\mathrm{Cp}$ ligand could also take place from the reaction of 1 on silica, we performed grafting experiments with a mixture of perdeuterated $\left(\mathbf{1}_{\mathrm{d} 10}\right)$ and non-labeled chromocene (1) (see SI Section 2.4 for details). The corresponding IR spectrum (Fig. 3B, top spectrum) clearly show the presence of $\mathrm{sp}^{2} \mathrm{C}-\mathrm{D}$ vibrational modes around $2300 \mathrm{~cm}^{-1}$, arising from the deuterated $\mathrm{Cp}$ ring. At the same time, we observed a band at $2761 \mathrm{~cm}^{-1}$, which is associated with the Si-OD groups; this is an evidence of OH/OD exchange within the surface hydroxyl groups upon addition of $\mathbf{1}_{\mathrm{d} 10}$. As a first possibility, such $\mathrm{H} / \mathrm{D}$ scrambling between the deuterated $\mathrm{Cp}$ ligand and the surface hydroxyl groups could arise from the protonation of the ring upon grafting. Alternatively, as inspired by the Mo analogs, ${ }^{32}$ the scrambling could also result from an internal C-D activation at the deuterated $\mathrm{Cp}$ ring of chemisorbed $\mathbf{1}_{\mathrm{d} 10}$ near $\mathbf{1}$.

To verify this proposal, we investigated the possible $\mathrm{C}-\mathrm{H}$ activation at the $\mathrm{Cp}$ ligand by subsequent grafting of protonated and deuterated complexes $\mathbf{1}$ and $\mathbf{1}_{\mathrm{d} 10}$ and vice versa (Fig. 3A). If the proposed $\mathrm{C}-\mathrm{H}$ activation occurs, the activated $\mathrm{H}$ atom would be accessible for an exchange with surface $\mathrm{OH}$ groups, resulting in the appearance of IR bands corresponding to Si-OD groups. It appeared that the grafting of $\mathbf{1}(0.25 \mathrm{wt}$. \% $\mathrm{Cr}$ ), that would result in a formation of protonated mono-grafted sites (see also Fig. 3A, top), followed by grafting of $\mathbf{1}_{\mathrm{d} 10}(0.75 \mathrm{wt}$. \% Cr, labeled as $\mathbf{1}_{\mathrm{hl}-\mathrm{d}-\mathrm{SiO}}-\mathbf{1}$ ), results in significantly more $\mathrm{OH} / \mathrm{OD}$ scrambling compared to the opposite case (see Fig. 3A bottom, 0.25 wt. \% $\mathbf{1}_{\mathrm{d} 10} \& 0.75$ wt. \% $\mathbf{1}$, labeled as $\left.\mathbf{1}_{1 \mathrm{II}-\mathrm{d}}-\mathbf{S i O} \mathbf{O}_{\mathbf{2}}-\mathbf{1}\right)$, as indicated by the much more intense IR bands corresponding to the Si-OD group (Fig. 3B). This suggests that the main source of H/D atoms for the observed $\mathrm{OH} / \mathrm{OD}$ scrambling is the $\mathrm{Cp}$ ring of the chemisorbed $\mathbf{1}$, which is present at higher $\mathrm{Cr}$ loadings. We thus propose that the observed OH/OD exchange mainly arises from the C-D activation at the Cp ring of the chemisorbed $\mathbf{1}_{\mathrm{d} 10}$, which provides easily accessible bridging hydride H/D atoms in analogy to the previously reported bridging $\mathrm{Mo}$ (III)-hydride complex, ${ }^{23}$ and consistently with the proposed $\mathrm{C}-\mathrm{H}$ activation pathway (Fig. 3A). This hypothesis is supported by EP studies on the prepared materials: after the polymerization of $\mathrm{C}_{2} \mathrm{H}_{4}$ with the $\mathbf{1}_{1 \mathrm{II}-\mathrm{d}}-\mathrm{SiO}_{\mathbf{2}}-\mathbf{1}$ material 
(consisting of grafted $\mathbf{1}_{\mathrm{d} 10}$ and chemisorbed $\mathbf{1}$ ), only trace amounts of $-\mathrm{CH}_{2} \mathrm{D}$ end groups are observed in the IR spectrum (Fig. S14), while after the polymerization of $\mathrm{C}_{2} \mathrm{D}_{4}$, mainly $-\mathrm{CD}_{2} \mathrm{H}$ end groups are observed. This indicates the initial ethylene insertion into the $\mathrm{Cr}-\mathrm{H}$ bond for these materials (see SI Section 3.3.1 \& Fig. S14).

In contrast, the material $\mathbf{1}_{\mathrm{hl}-\mathrm{d}}-\mathrm{SiO}_{\mathbf{2}} \mathbf{- 1}$ (consisting of grafted $\mathbf{1}$ and chemisorbed $\mathbf{1}_{\mathrm{d} 10}$ ), shows the presence of $-\mathrm{CH}_{2} \mathrm{D}$ ending groups after the polymerization of non-labeled $\mathrm{C}_{2} \mathrm{H}_{4}$, indicating the formation of $\mathrm{Cr}$ - $\mathrm{D}$ bonds in case of the presence of chemisorbed $\mathbf{1}_{\mathrm{d} 10}$. Therefore, the hydrogen atom for the formation of the $\mathrm{Cr}-\mathrm{H}$ hydride species is delivered from the $\mathrm{Cp}$ ring of the chemisorbed 1, consistent with the proposed mechanism (Fig. $3 \mathrm{~A}$ ) and the calculated pathway of its formation (vide infra). At the same time, the obtained dimeric, bridging $\mathrm{Cr}(\mathrm{III})$ hydride species (see Fig. 3A) shall be EPR silent due to a strong exchange between the neighboring $\mathrm{Cr}$ (III) centers. This would contradict the observation of $\mathrm{Cr}$ (III) sites that are active in EP as evidenced by CW EPR (see Fig. S13). Therefore, we suggest that the dimeric, bridging $\mathrm{Cr}$ (III) hydride species (Fig. 3A) split apart to form monomeric $\mathrm{Cr}(\mathrm{III})$ sites involving hydroxyl groups from the silica surface (vide infra).

In order to further support the mechanism of the $\mathrm{Cr}$ (III) hydride formation in the UC catalysts, we performed DFT studies for possible reaction pathways of the reaction of 1 with the silica surface $\left(\right.$ modelled by RO $\left.=-\mathrm{Si}(\mathrm{OH})_{3}\right)$. The structures of the $\mathrm{Cr}$ species (see Tables S5 \& S6 for the DFT-optimized structures of all Cr species in this study), were optimized using open-shell calculations with the B3LYP functional (see SI for the computational details and optimization of the computational method and Table S4) and the spin state with the lowest energy was selected (see Table S7). Dimeric species were optimized using the broken symmetry approach. 
A
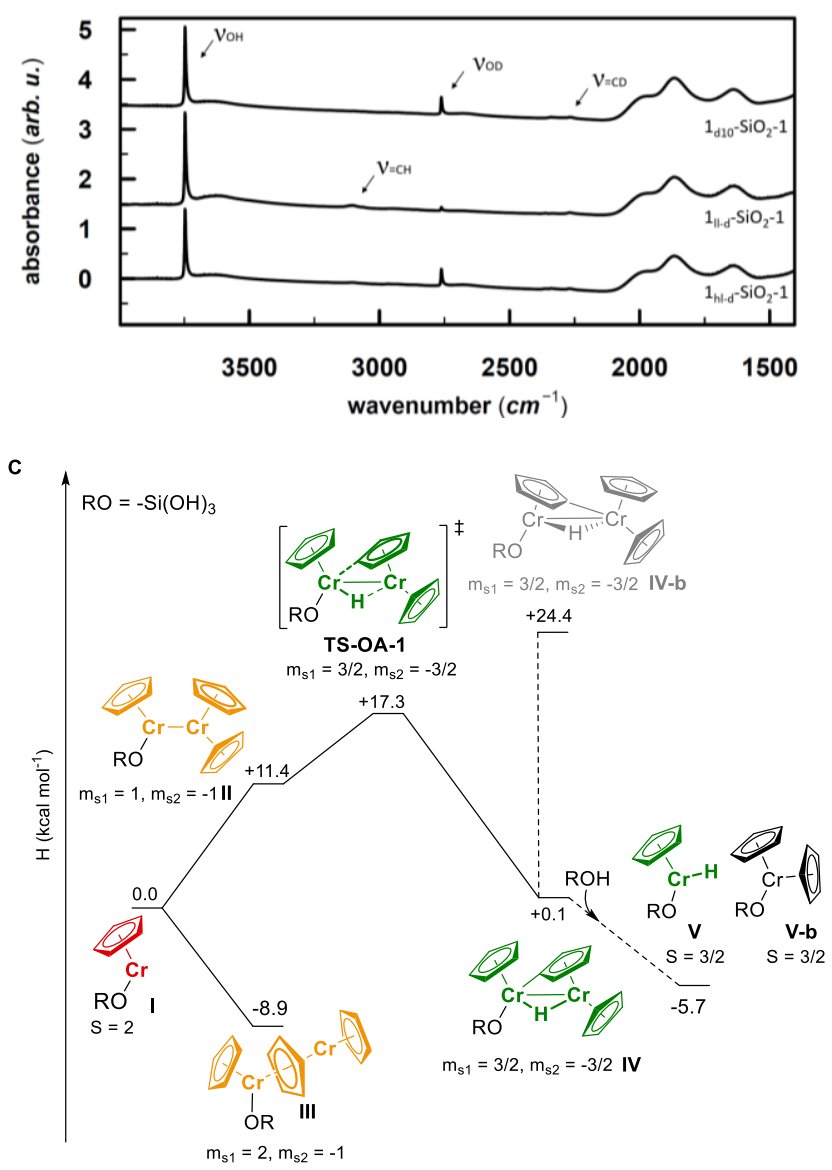

Figure 3. A) Proposed formation pathway of the bridging $\mathrm{Cr}(\mathrm{III})$-hydrides, based on ${ }^{2} \mathrm{H}$-labeling studies with $\mathbf{1}_{\mathrm{d} 10}$. The ${ }^{2} \mathrm{H}$-labeled $\mathrm{Cp}$ rings are marked in blue. B) IR spectra of ${ }^{2} \mathrm{H}$-labeled (top) and mixed ${ }^{1} \mathrm{H} /{ }^{2} \mathrm{H}$ labeled UC materials below. $\mathbf{1}_{\mathrm{II-d}}-\mathrm{SiO}_{2}-\mathbf{1}$ corresponds to the material that is first exposed to $\mathbf{1}_{\mathrm{d} 10}(0.25 \mathrm{wt}$. $\% \mathrm{Cr})$ to form mono-grafted sites, followed by $\mathbf{1}$ ( 0.75 wt. \%; see also Fig. 3A, bottom). In contrary, $\mathbf{1}_{\text {hl-d-SiO}}-\mathbf{S}-\mathbf{1}$ corresponds to 0.25 wt. $\% \mathbf{1}$ and 0.75 wt. \% $\mathbf{1}_{\mathrm{d} 10}$. C) Proposed reaction pathways for the interaction of 1 on partially dehydroxylated silica $\mathrm{SiO}_{2-700}$ for low and high $\mathrm{Cr}$ loading. Enthalpies $\left(H \mathrm{kcal} \mathrm{mol}^{-1}\right.$ ) are calculated with respect to I and $\mathrm{CrCp}$ (see the SI for the computational details). For monomeric sites, the spin quantum number is indicated with $\mathrm{S}$, for dimeric sites, which were optimized using a broken symmetry calculation, the local projection of the spin, as obtained from the Mulliken spin density on $[\mathrm{CrCp}]$ fragments $\mathrm{I}$, is shown with $\mathrm{m}_{\mathrm{si}}$.

The high-spin ( $S=2$ ) mono-grafted site I (see Fig. $3 \mathrm{C}$ and Table $\mathrm{S7}$ ), has a coordinative unsaturation that may be fulfilled by interaction with adjacent $\mathrm{Si}-\mathrm{O}-\mathrm{Si}$ bridges or surface $\mathrm{OH}$ groups for the $\mathrm{UC}$ materials with low $\mathrm{Cr}$ loading. At higher $\mathrm{Cr}$ loading, site I can also interact with another molecule of $\mathbf{1}$, either to form stacked metallocene complex III $\left(\Delta H=-8.9 \mathrm{kcal} \mathrm{mol}^{-1}\right)$, or complex II with a direct $\mathrm{Cr}-\mathrm{Cr}$ bond (site II, $\left.\Delta H=+11.4 \mathrm{kcal} \mathrm{mol}^{-1}\right)$. Sites II can further reorganize through $\mathrm{C}-\mathrm{H}$ activation at the $\mathrm{Cp}$ ring, (see Fig. $3 \mathrm{C}$ ), yielding the surface site IV, a bridging $\mathrm{Cr}$ (III)hydride complex, with a transition state barrier of $\Delta H^{*}=+17.3 \mathrm{kcal} \mathrm{mol}^{-1}$ (TS-OA-1, see Fig. 3C) with respect to 1 . Note that the obtained product IV results from $\mathrm{C}-\mathrm{H}$ activation at the $\mathrm{Cp}$ ring of the chemisorbed 1; $a$ contrario, 
the $\mathrm{C}-\mathrm{H}$ activation at the ( $\equiv \mathrm{SiO})-\mathrm{CrCp}$ moiety by $\mathbf{1}$ would lead to the formation of surface site IV-b, that is energetically strongly disfavored $\left(\Delta H=+24.4 \mathrm{kcal} \mathrm{mol}^{-1}\right.$ with respect to 1$)$. This is consistent with the labeling studies, where no IR bands from the surface Si-OD groups were detected after the interaction of deuterated mono-grafted sites with non-labeled chemisorbed $\mathbf{1}$ (see Fig. 3B). The hydride in surface site IV is located closer to the second $\mathrm{Cr}$ center, so that the two $\mathrm{Cr}$ atoms are calculated to be formally in oxidation state (III) (with three unpaired electrons per $\mathrm{Cr}$ atom) rather than (IV) and (II) as in the case of Mo. ${ }^{32}$ The presence of a small amount of Brønsted acid sites on silica (i.e. surface hydroxyl groups) may result in further protonation of the site IV, leading to the formation of the energetically favored $\left(\Delta H=-5.8 \mathrm{kcal} \mathrm{mol}^{-1}\right)$ monomeric $\mathrm{Cr}(\mathrm{III})$ hydride $\mathbf{V}$ and $\mathrm{Cr}(\mathrm{III})$ site $\mathbf{V}$ b, as shown in Fig. 3C. Based on these computational results, we propose the formation of $\mathrm{Cr}$ (III) hydrides upon contact of 1 with dehydroxylated silica at high loading, i.e. during the preparation of the UC catalysts. This is consistent with the fact that $\mathrm{Cr}$ (III) species were detected in the UC system by EPR spectroscopy (see Fig. S13).

All the proposed surface species I - V can coordinate CO molecules or perform the CO insertion into the $\mathrm{Cr}-\mathrm{H}$ bond in the case of the $\mathrm{Cr}(\mathrm{III})$ hydrides, resulting in characteristic IR bands. Thus, we then focused on calculations of the CO vibrational frequencies (see SI Section 3.2, Fig. S15 \& Table S8 for the details of computations) of all possible $\mathrm{Cr}$ species after $\mathrm{CO}$ coordination to verify our previous assignments for the experimental IR spectra (see Part 1). The calculated IR frequencies (see Fig. S16 and Table S9 for all DFT-computed IR frequencies for all surface sites) were then compared to the deconvoluted IR spectra after the CO adsorption (see Fig. S17-S25 and S28 and Tables S10-S13).

As follows from its coordinative unsaturation, site I can easily accommodate one (I-CO-1) or two CO molecules (ICO-2; see Fig. S17 \& S28). For I-CO-1, DFT calculations predict a CO vibrational band at $1964 \mathrm{~cm}^{-1}$, whereas for ICO-2, two CO bands, corresponding to the symmetric and antisymmetric distortion respectively at $2027 \mathrm{~cm}^{-1}$ and $1973 \mathrm{~cm}^{-1}$, are expected. This is in good agreement with the experimental values obtained for $\mathbf{1}-\mathrm{SiO}_{2}-\mathbf{0 . 2 5}$ with the two main peaks at $2061 \mathrm{~cm}^{-1}$ and $1981 \mathrm{~cm}^{-1}$ (see Fig. S18 \& Table S10), and the shoulder of low intensity at $1993 \mathrm{~cm}^{-1}$ that would correspond to I-CO-1 species (see Fig. S17, indicated with “*”). At higher Cr loadings, 1 chemisorbs to the monomeric $\mathrm{Cr}$ (II) sites I giving rise to two sorts of dimers with strong (site II) and weak $\mathrm{Cr}$ - $\mathrm{Cr}$ interactions (site III), as shown in Fig. 3C. Site II can accommodate up to three CO molecules. The terminal-like CO band at $2097 \mathrm{~cm}^{-1}$ is likely related to the experimental signal at $2014 \mathrm{~cm}^{-1}$ in 1-SiO2-1.

Two additional CO bands are calculated at $1918 \mathrm{~cm}^{-1}$ and $1824 \mathrm{~cm}^{-1}$, indicative of strongly bridging CO molecules. In the IR spectrum of the UC catalyst 1-SiO ${ }_{2}^{-1}$, two broad CO bands appear around $1905 \mathrm{~cm}^{-1}$ and $1837 \mathrm{~cm}^{-1}$ (see Fig. S28), consistent with the two bridging CO bands of site II-CO-2 and II-CO-3 (Fig. S2O \& S28). In the case of a bridging mono-carbonyl (II-CO-1), the "bridging CO character" increases and gives rise to a calculated low energy $\mathrm{CO}$ band with a calculated frequency of $1777 \mathrm{~cm}^{-1}$. This prediction is consistent with the experimentally observed broad band of weak intensity at around $1742 \mathrm{~cm}^{-1}$ that appears in 1-SiO ${ }_{2}^{-1}$ (Fig. S23 \& S28, see also Table S12) and 1-SiO ${ }_{2}-\mathbf{2}$ (Fig. S24 \& Table S13). Surface site III can coordinate one CO molecule that, according to calculations $\left(2065 \mathrm{~cm}^{-1}\right)$, falls in the range of predicted terminal-like CO vibrations (see Fig. S25). Coordination of more than one CO molecule does split site III into I-CO-2 and $\mathbf{1}$ (see Figs. S26 \& S27). Finally, CO insertion into the $\mathrm{Cr}-\mathrm{H}$ bond of surface site IV is energetically favored $\left(\Delta H=-6.2 \mathrm{kcal} \mathrm{mol}^{-1}\right)$, yielding site IV-CO-1 with a calculated CO vibrational frequency of $1642 \mathrm{~cm}^{-1}$. This agrees with the experimentally observed broad band at $1630 \mathrm{~cm}^{-1}$, as shown in Fig. S28. Similar to the surface site IV, the monomeric $\mathbf{C r}($ III)-hydride model complex $\mathbf{V}$ can also insert one CO molecule (V-CO-1); such an insertion is strongly favored $\left(\Delta H=-87.2 \mathrm{kcal} \mathrm{mol}^{-1}\right)$. The vibrational frequency of this site is calculated to be at $1546 \mathrm{~cm}^{-1}$, which is close to the experimentally observed broad band of low intensity at $1579 \mathrm{~cm}^{-1}$ (see Fig. S28). This further support that the signals observed at low frequencies and related to the EP activity are likely due to $\mathrm{Cr}(\mathrm{III})$ hydrides. 
As outlined above, the EP activity of the UC catalyst correlates with the appearance of the dimeric (IV) and monomeric (V) $\mathrm{Cr}$ (III) hydrides (see Part 2). Therefore, either monomeric or dimeric $\mathrm{Cr}$ (III) hydrides could be the active site(s). We then calculated the energy barrier for the activation of ethylene and further chain propagation during EP on dimeric and monomeric $\mathrm{Cr}$ (III) hydrides (see Figs. S30 \& 4 respectively).

Ethylene coordination to the coordinatively unsaturated monomeric $\mathrm{Cr}$ (III) hydride $\mathbf{V}$ is energetically favorable (V$\left.\mathbf{H}-\mathrm{C}_{2} \mathrm{H}_{4}, \Delta H=-7.6 \mathrm{kcal} \mathrm{mol}^{-1}\right)$, and further $\mathrm{C}_{2} \mathrm{H}_{4}$ insertion into the $\mathrm{Cr}-\mathrm{H}$ bond is nearly barrier-less $\left(\Delta H^{+}=1.1 \mathrm{kcal}\right.$ $\mathrm{mol}^{-1}$, Fig. 4). The resulting monomeric $\mathrm{Cr}(\mathrm{III})$ alkyl V-ethyl, whose formation is strongly favored $(\Delta H=-16.3 \mathrm{kcal}$ $\mathrm{mol}^{-1}$ for $\mathrm{V}-\mathrm{H}-\mathrm{C}_{2} \mathrm{H}_{4}$ ), can now undergo chain growth via the subsequent ethylene insertions into the $\mathrm{Cr}-\mathrm{C}$ bond, according to the Cossee-Arlman mechanism. ${ }^{20}, 33$ Such an ethylene polymerization on $\mathrm{Cr}$ (III) hydrides is reminiscent to EP-active Ti(III) hydrides, for which the formation of Ti(III) alkyl species after the contact with ethylene has been evidenced. ${ }^{15}$ Moreover, the obtained monomeric $\mathrm{Cr}(\mathrm{III})$ alkyl species (V-ethyl) are likely highly active in EP, according to the "augmented" Cossee-Arlman mechanism, previously described for the EP-active well-defined Ti(III) alkyls ${ }^{25}$ and for heterogeneous Ziegler-Natta catalysts. ${ }^{10}$ After the formation of the $\mathrm{Cr}$ (III) alkyl V-ethyl species, the subsequent ethylene insertion has a relatively low calculated TS barrier of $\Delta H=12.1 \mathrm{kcal} \mathrm{mol}^{-}$ ${ }^{1}$ (see Fig. 4A). Alternatively, the monomeric $\mathrm{Cr}(\mathrm{III})$ alkyl species V-ethyl can be formed by protonation of the dimeric surface site VIII (Fig. 4B), with nearby surface hydroxyl groups.

A

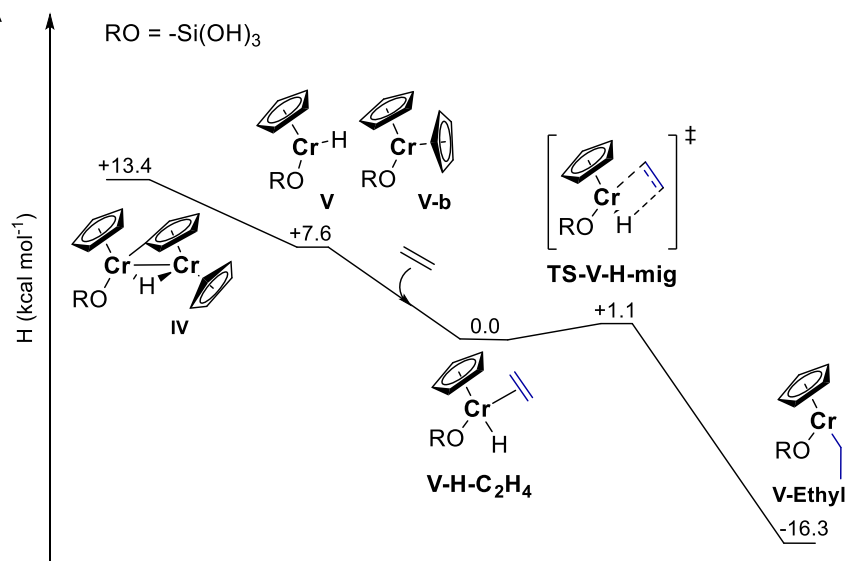

B

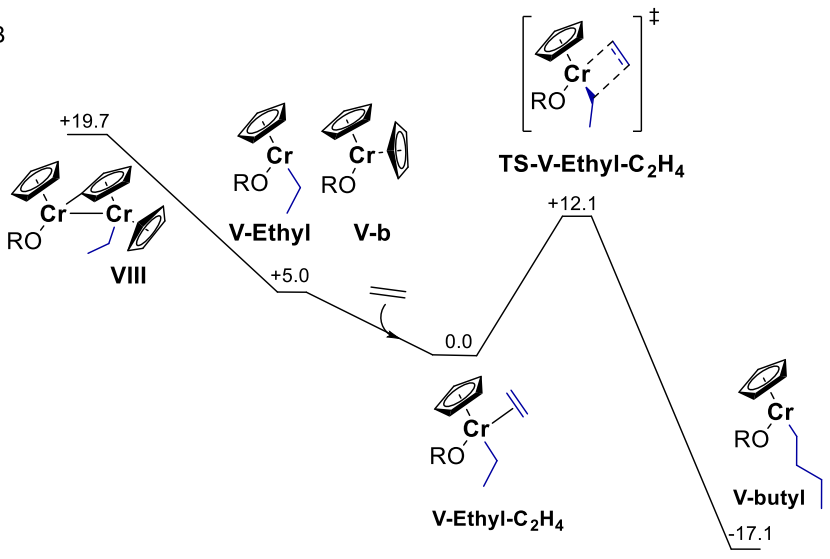

Figure 4. Calculated reaction enthalpies for potential ethylene activation pathways involving monomeric $\mathrm{Cr}$ (III) hydrides such as $\mathbf{V}(\mathrm{A})$, or monomeric $\mathrm{Cr}(\mathrm{III})$ alkyl species such as $\mathbf{V}$-ethyl (B). Ethylene activation and chain propagation are both associated with reasonable energy costs.

Regarding dimeric $\mathrm{Cr}$ (III) hydride IV, ethylene can coordinate to the $\mathrm{Cr}$ atom grafted on the silica surface, while the initially bridging hydride is now localized on the $\mathrm{C}-\mathrm{H}$ activated chromocene fragment in complex $\mathrm{VI}-\mathrm{a}$ (see Fig. S30). The hydride can migrate to ethylene while the first $\mathrm{Cr}-\mathrm{C}$ bond is formed (TS-mig-1), leading to the dimeric $\mathrm{Cr}$ (III) alkyl complex VII. Chain propagation can take place either on one (TS-[2+2]) or two chromium centers (TSmig-2). Migration of the alkyl moiety prior to the coordination of ethylene (IX-a) is energetically feasible, while direct coordination of ethylene in absence of chain migration is less favored (IX-b). Overall, both binuclear $\mathrm{Cr}$ mediated chain propagation pathways are associated with high energy costs due to the geometry of the TS (TSmig-2) that imposes a $\mathrm{Cr}-\mathrm{C}$ bond dissociation, which is rather unlikely. Alternatively, TS-[2+2] would allow for a simultaneous formation and breaking of the $\mathrm{Cr}-\mathrm{C}$ bond. However, the pentacoordinate transition state is located very high in energy. According to these results, the formation of a dimeric $\mathrm{Cr}$ (III) alkyl site VII is possible; however, further chain propagation and EP on this site is unlikely from an energy point of view. 
At the same time, monomeric and dimeric $\mathrm{Cr}(\mathrm{II})$ model systems $\mathbf{2}-\mathbf{S i O}_{\mathbf{2}}$ and $\mathbf{3}-\mathbf{S i O}_{\mathbf{2}}$ are inactive in $\mathrm{EP}$; this is consistent with our DFT calculations, which show that monomeric $\mathrm{Cr}(\mathrm{II})$ surface sites such as I should be inactive in EP (see SI Section 3.3 \& Fig. S29).

\section{Synthesis and characterization of well-defined silica-supported $\mathrm{Cr}$ (III) alkyl analogs to the Union Carbide EP catalyst}

The combination of experimental and computational studies indicate the role of monomeric surface $\mathrm{Cr}$ (III) hydrides as precursors for the active species of the UC catalysts, yielding the propagating $\mathrm{Cr}$ (III) alkyls, upon insertion of ethylene. Inspired by the work of Theopold et al., who reported the synthesis of the monomeric $\left[\mathrm{Cp} * \mathrm{Cr}\left(\mathrm{CH}_{2} \mathrm{SiMe}_{3}\right)_{2}\right]$ complex, ${ }^{34,}{ }^{35}$ we developed the corresponding parent $\mathrm{Cp}$ derivative $\mathrm{CpCr}\left[\left(\mathrm{CH}\left(\mathrm{SiMe}_{3}\right)_{2}\right)\right](4)$ that is accessible by using the bulky $-\mathrm{CH}\left(\mathrm{SiMe}_{3}\right)_{2}$ ligands (see Fig. $5 \mathrm{~A}$ ). The reaction of $\left[\mathrm{CpCrCl}_{2}\right]_{2}$ with two equivalents of $\mathrm{LiCH}\left(\mathrm{SiMe}_{3}\right)_{2}$ yields a dark red oil; while the complex is analytically pure by NMR, consistent with complex 4. However, we were not able to obtain high quality crystals for X-ray diffraction studies (see SI Section $4.1 \&$ Fig. S31 for details on the synthesis and characterization).

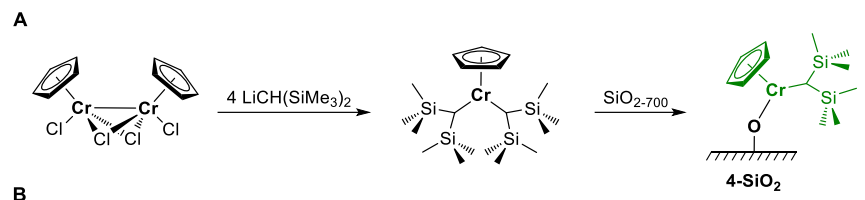

B

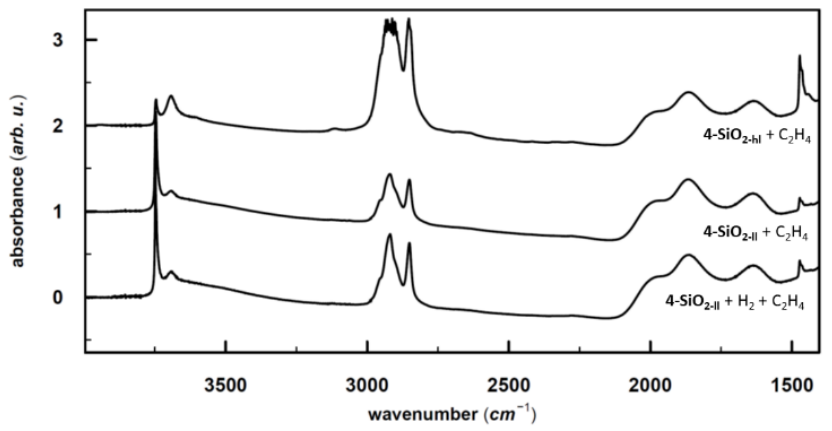

Figure 5. A): Synthesis and surface chemistry of monomeric $\mathrm{Cr}(\mathrm{III})$ alkyl complexes. B) IR spectra of $\mathbf{4}_{-} \mathrm{SiO}_{2}$ with high $\mathrm{Cr}$ loading ( $0.8 \mathrm{wt}$. \%) after exposure to $25 \mathrm{mbar}$ of ethylene (top), and $4-\mathrm{SiO}_{2}$ with low $\mathrm{Cr}$ loading (0.2 wt. \%) after exposure to ethylene (middle) and $\mathrm{H}_{2}$ (50 mbar) prior to ethylene (bottom). The higher intensity of $\mathrm{C}-\mathrm{H}$ bands after exposure of low $\mathrm{Cr}$-loading material to $\mathrm{H}_{2}$ evidence for slightly higher EP activity.

Upon contacting a benzene solution of $\mathbf{4}$ with partially dehydroxylated silica $\left(\mathrm{SiO}_{2-700}\right)$, the material instantaneously turned purple, while releasing $\mathrm{H}_{2} \mathrm{C}\left(\mathrm{SiMe}_{3}\right)_{2}$ to the washing solution. The IR spectrum of 4-SiO shows two intense bands at $3126 \mathrm{~cm}^{-1}(=\mathrm{C}-\mathrm{H})$, and $2955 \mathrm{~cm}^{-1}\left(-\mathrm{CH}_{3}\right)$, indicating the presence of the $\left[\mathrm{CH}\left(\mathrm{SiMe}_{3}\right)_{2}\right]$ ligand in the obtained grafted species (see Figs. S4 \& S32 for its XAS and IR characterization). This is consistent with the formation of surface alkyl species $(\equiv \mathrm{SiO}) \mathrm{CrCp}\left[\mathrm{CH}\left(\mathrm{SiMe}_{3}\right)_{2}\right]$, which has a structure close to the proposed active sites, V-ethyl, that contains one propagating alkyl chain. In fact, upon exposure to ethylene (100 mbar of $\mathrm{C}_{2} \mathrm{H}_{4}, 12 \mathrm{mg}$ of the sample), 4-SiO ${ }_{2}$ rapidly generates a large amount of polyethylene and further evidenced by the appearance of strong $\mathrm{C}-\mathrm{H}$ bands in the IR spectrum (see Fig. 5B). The polyethylene produced exhibits similar properties, i.e. $M_{w}=3610, \emptyset=23.7$, as the one produced by the industrial-like UC catalyst under the same conditions $\left(M_{w}=3700, \emptyset=23.5\right.$, see Table S15). This strongly indicates that the obtained material 4-SiO $\mathbf{2}_{2}$ and the UC catalyst contain the same type of active sites.

We further characterized the 4-SiO ${ }_{2}$ material with EPR spectroscopy as it was previously used for the investigation of EP catalysts. ${ }^{33,36-38}$ The CW EPR spectrum ${ }^{39}$ of 4-SiO ${ }_{2}$ taken at $5 \mathrm{~K}$ (Fig. 6A, black) shows the presence of multiple HS (120 - $240 \mathrm{mT}$ region) and two LS (300 - $400 \mathrm{mT}$ region) $\mathrm{Cr}$ (III) species. According to previous studies, ${ }^{27}$ silica- 
supported $\mathrm{Cr}$ (III) HS species are characterized by a ZFS that exceeds Zeeman interaction at typical magnetic fields by far and, therefore, by an effective $g$ tensor $(g \perp \sim 4, g \| \sim 2)$. This limits the possibility for their assignment based on the comparison of $g$ tensor values or of exact parameters (D or E) of the ZFS tensor. In this situation, the CW EPR spectra inform only on the E/D ratio, whereas absolute values of the parameters cannot be obtained. ${ }^{31}$ In our case, the major fraction is represented by a single line in the $g \sim 4$ region, which suggests relatively small E/D values close to 0 and is thus indicative of nearly axial symmetry. In contrast, the LS species are best simulated with an orthorhombic $g$ tensor of $g_{x}=1.9916, g_{y}=2.0028, g_{z}=2.0157$ (Fig. 6A, blue). We then propose that for the obtained $4-\mathrm{SiO}_{2}$ system, the axially symmetric $\mathrm{HS}$ species can be assigned to the mono-grafted axially symmetric $(\equiv \mathrm{SiO}) \mathrm{CrCp}\left[\mathrm{CH}\left(\mathrm{SiMe}_{3}\right)_{2}\right]$ surface complex, while the LS species are likely associated with the same organometallic fragment but involve additional interactions of the $\mathrm{Cr}$ center with nearby Si-O-S siloxane bridges. In fact, the obtained $g$ tensor principal values for this LS species $(g=[1.9916 ; 2.0028 ; 2.0157])$ are rather close to those, obtained for the $\mathrm{Cr}(\mathrm{III})$ species of the original UC catalyst $1-\mathrm{SiO}_{2}-\mathbf{1}$ after its contact with $\mathrm{C}_{2} \mathrm{H}_{4}(g=[1.9900$; $2.0025 ; 2.0184])$.

We then focused on pulse EPR investigations of the $S=1 / 2$ species $\left(g_{\mathrm{x}}=1.9916, g_{\mathrm{y}}=2.0028, g_{\mathrm{z}}=2.0157\right)$, as its transverse relaxation time $T_{2}=167 \mathrm{~ns}(5 \mathrm{~K})$ allows to obtain a good signal intensity at such temperatures. As seen from the echo-detected EPR spectrum of 4-SiO $_{2}$ (Fig. 6A), in pulse EPR spectroscopy only the LS component is observable under these conditions, which enables the selective characterization of this species by $2 \mathrm{D}$ hyperfine sublevel correlation (HYSCORE) spectroscopy. ${ }^{40}$ The HYSCORE spectra (Fig. 6B, C) reveal the presence of hydrogen atoms, magnetically coupled to $\mathrm{Cr}(\mathrm{III})$ centers, as well as weak couplings to ${ }^{29} \mathrm{Si}$ and ${ }^{13} \mathrm{C}$ nuclei. The observation of ${ }^{13} \mathrm{C}$ signals for $\mathbf{4}_{-} \mathrm{SiO}_{2}$ in the absence of ${ }^{13} \mathrm{C}$ labeling is indicative for complexes with aromatic ligands, and thus suggests the presence of coordinated $\mathrm{Cp}$ ligand within the $\operatorname{LS} \operatorname{Cr}(I I I)(g=[1.9916 ; 2.0028 ; 2.0157])$ species. However, the resolution is limited here, due to the proximity of possible ${ }^{29} \mathrm{Si}$ peaks. In contrast, for ${ }^{1} \mathrm{H}$, spectral simulation of the observed hyperfine couplings (Fig. 6C) allowed us to extract the principal values of the ${ }^{1} \mathrm{H}$ hyperfine coupling tensor $\left(\mathrm{a}_{\text {iso }}=3.0 \mathrm{MHz}, \mathrm{a}_{\text {dip }}=[-4.75-4.759 .5] \mathrm{MHz}\right)$, when assuming axial symmetry. Using the point-dipole approximation, ${ }^{15}$ we determined the $\mathrm{Cr}(\mathrm{III})-\mathrm{H}$ distance to be $2.55 \AA$; such distances and hyperfine coupling tensor parameters are typical for the $\alpha-\mathrm{H}$ atoms of bis-trimethylsilylmethyl ligands in metal-alkyl complexes. ${ }^{33,41}$

This allows us to assign the observed $\mathrm{S}=1 / 2\left(g=[1.9916 ; 2.0028 ; 2.0157)\right.$ species to $(\equiv \mathrm{SiO}) \mathrm{CrCp}\left[\mathrm{CH}\left(\mathrm{SiMe}_{3}\right)_{2}\right]$ surface sites, which are likely affected by additional $\mathrm{Cr}-\mathrm{O}$ interactions with nearby siloxane bridges. A similarity in $g$ tensor principal values with those of $1-\mathrm{SiO}_{2}-\mathbf{1}$ in the presence of ethylene (see Part 1) allows us to propose that the similar $(\equiv \mathrm{SiO}) \mathrm{CrCp}-\mathrm{R}$ species $\left(\mathrm{R}=-\left(\mathrm{CH}_{2}\right)_{n}-\mathrm{CH}_{3}\right)$ are formed in the UC system after its contact with ethylene, and that the proposed structure is the active site of the UC catalyst. 


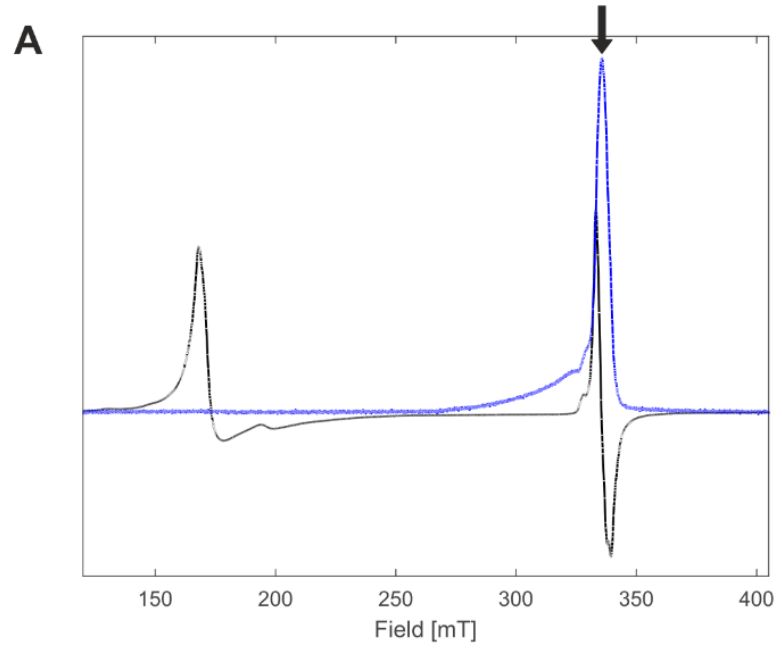

B

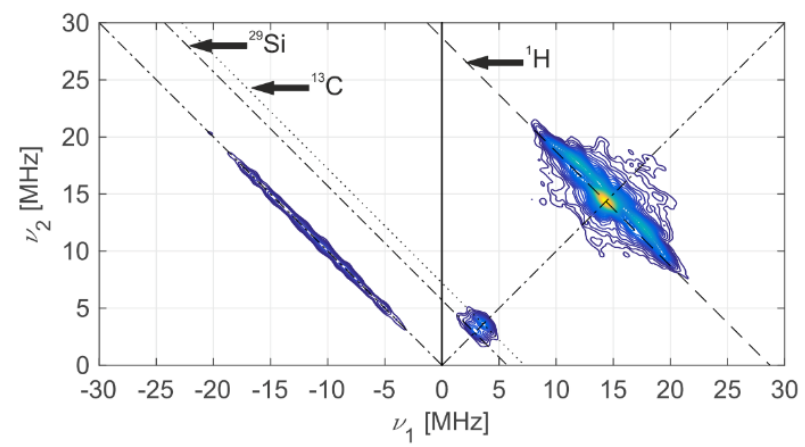

C

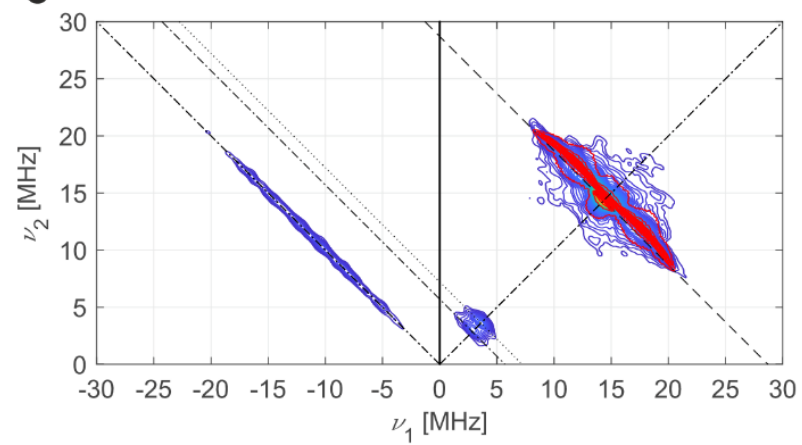

D

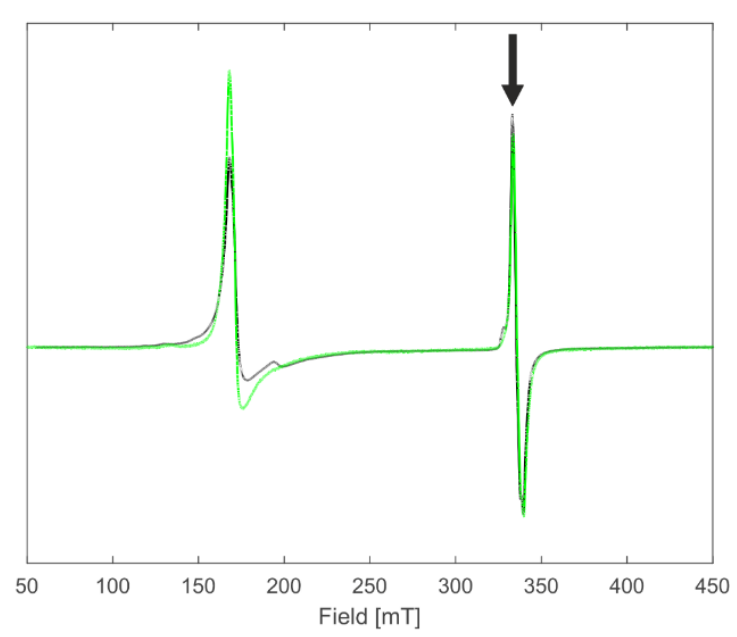

E

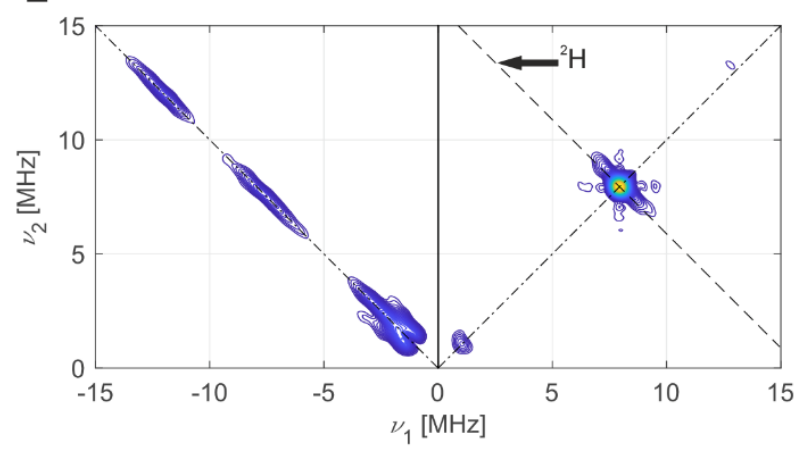

$\mathbf{F}$

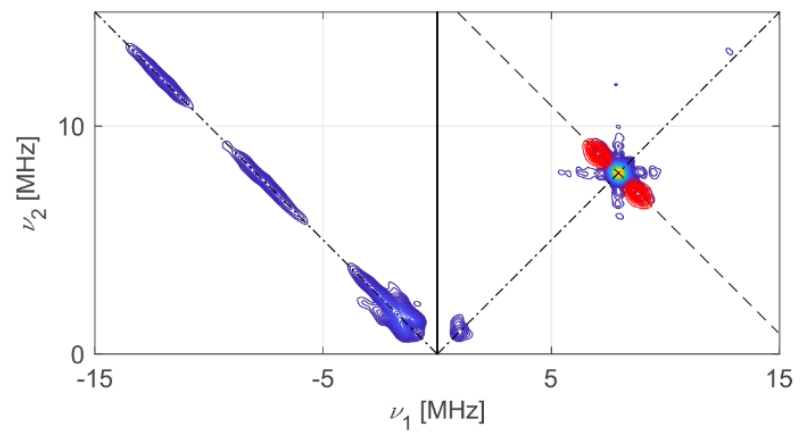

Figure 6. A) CW EPR spectrum (black) and echo-detected EPR spectrum (blue) of 4-SiO ${ }_{2}$, measured at $5 \mathrm{~K}$. The black arrow indicates the field position for HYSCORE. B) HYSCORE spectrum (blue to yellow) of 4-SiO ${ }_{2}$, measured at $5 \mathrm{~K}$. Antidiagonal lines indicate nuclear Zeeman frequencies of magnetically coupled nuclei that are present in this system. C) Overlay of simulated (red) ${ }^{2} \mathrm{H}$ hyperfine couplings with the experimental HYSCORE spectrum (blue to yellow) from B) with an overall good agreement to the experimental spectrum. For details on the measurement conditions see the method Section of the SI. D) CW EPR spectra of 4-SiO $\mathbf{2}_{2}$ before (black) and after (green) the EP. The black arrow indicates the field position used for HYSCORE. E) Q-band HYSCORE spectrum (blue to yellow) of 4-SiO ${ }_{2}$ after the $\mathrm{C}_{2} \mathrm{D}_{4}$ exposure. F) Overlay of simulated (red) ${ }^{2} \mathrm{H}$ hyperfine couplings with the experimental HYSCORE spectrum (blue to yellow) from $\mathrm{E}$ ) with an overall good agreement to the experimental spectrum. 
To further support this hypothesis, we performed EPR spectroscopic studies of 4-SiO $\mathbf{O}_{2}$ after its contact with ${ }^{2} \mathrm{H}$-labeled ethylene $\mathrm{C}_{2} \mathrm{D}_{4}$. We observed unchanged principal $g$ tensor values of the investigated LS species $\left(g_{\mathrm{x}}\right.$ $=1.9916, g_{\mathrm{y}}=2.0028, g_{\mathrm{z}}=2.0157$ ) after exposure to $\mathrm{C}_{2} \mathrm{D}_{4}$ (Fig. $6 \mathrm{D}$ ). After the contact with $\mathrm{C}_{2} \mathrm{D}_{4}$, we observed the appearance of ${ }^{2} \mathrm{H}$ hyperfine couplings in its Q-band HYSCORE spectrum (Fig. $6 \mathrm{E}$ ), with $\mathrm{a}_{\text {iso }}=1.7 \mathrm{MHz}$, $\mathrm{a}_{\text {dip }}$ $=[-0.6-0.61 .2] \mathrm{MHz}$ and unresolved quadrupole coupling (Fig. 6F). This indicates that deuterium nuclei are in close proximity to the $\mathrm{Cr}$ (III) center, which is consistent with a $\mathrm{C}_{2} \mathrm{D}_{4}$ insertion into the $\mathrm{Cr}(\mathrm{III})$ - $\mathrm{C}$ bond during the ethylene polymerization, in agreement with the Cossee-Arlman mechanism ${ }^{20,33}$ (see Fig. 7). This is further confirmed by the disappearance of ${ }^{1} \mathrm{H}$ hyperfine couplings in the X-band HYSCORE spectrum of 4-SiO ${ }_{2}$ after the polymerization of $\mathrm{C}_{2} \mathrm{D}_{4}$ (see Fig. S36), indicating that hydrogen atoms are no longer close to the $\mathrm{Cr}(\mathrm{III})$ center upon contacting with $\mathrm{d}_{4}$-ethylene, consistent with its insertion into the $\mathrm{Cr}(\mathrm{III})-\mathrm{CH}\left(\mathrm{SiMe}_{3}\right)_{2}$ bond of 4$\mathrm{SiO}_{2}$ leading to the formation of $\mathrm{Cr}(\mathrm{III})-\left(\mathrm{CD}_{2}\right)_{\mathrm{n}}-\mathrm{CH}\left(\mathrm{SiMe}_{3}\right)$ species, as shown in Fig. 7. Therefore, we propose that the same Cossee-Arlman mechanism is involved in EP on the LS Cr(III) alkyl sites (e.g. V-ethyl) of the UC catalysts, which are formed after its contact with $\mathrm{C}_{2} \mathrm{H}_{4}$. Note that there is also a change in the CW EPR spectrum of the $\mathrm{HS} \mathrm{Cr}(\mathrm{III})$ species upon the contact of $4-\mathrm{SiO}_{2}$ with ethylene (Fig. 6D). This points towards the participation of the HS species in EP, despite the presence of additional interactions of $\mathrm{Cr}$ (III) centers with nearby Si-O-S siloxane bridges.

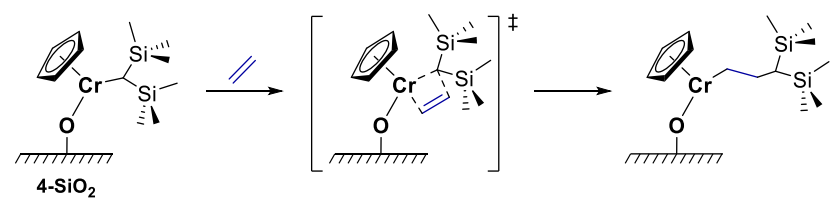

Figure 7. Proposed insertion of ethylene into the $\mathrm{Cr}(\mathrm{III})-\mathrm{CH}\left(\mathrm{SiMe}_{3}\right)_{2}$ bond of 4-SiO${ }_{2}$.

Overall, these findings indicate that the $4-\mathrm{SiO}_{2}$ material contains $(\equiv \mathrm{SiO}) \mathrm{CrCp}\left[\mathrm{CH}\left(\mathrm{SiMe}_{3}\right)_{2}\right]$ surface species, which are the active sites in EP. This is in agreement with previously reported (although without detailed EPR characterization) homogeneous monomeric, tri-coordinated $\mathrm{Cr}(\mathrm{III})$ alkyl complexes that are known to polymerize ethylene. ${ }^{13}$ This further corroborates our proposition for the monomeric surface $\mathrm{Cr}$ (III) hydride/alkyl species (V/V-ethyl) as the active sites of the UC catalysts.

\section{Conclusions}

In this work, we characterized surface sites of the Union Carbide silica-supported Cr-based ethylene polymerization catalyst, using SOMC in combination with IR and EPR spectroscopic investigations, labeling experiments, and computational studies. Using this approach, we identified various surface sites, whose speciation depends on the $\mathrm{Cr}$ loading. Monomeric $\mathrm{Cr}(\mathrm{II})$ species ( $\equiv \mathrm{SiO}) \mathrm{CrCp}$ are formed at very low $\mathrm{Cr}$ loading and show no polymerization activity. Increasing $\mathrm{Cr}$ loading leads to the formation of dimeric $\mathrm{Cr}$ (II) surface sites ( $\equiv \mathrm{SiO}) \mathrm{Cr}_{2} \mathrm{Cp}_{3}$ with various $\mathrm{Cr}$ - $\mathrm{Cr}$ interactions, that are also inactive towards EP. At higher loading, EPR, $\mathrm{IR}$, and labeling studies point to the formation of monomeric $\mathrm{Cr}(\mathrm{III})$ hydrides $(\equiv \mathrm{SiO}) \mathrm{CrCp}-\mathrm{H}$ whose presence correlates with EP activity. They are thus proposed to be the active sites of the UC catalyst. These species are formed via the $\mathrm{C}-\mathrm{H}$ activation at the $\mathrm{Cp}$ ring and involvement of surface hydroxyl groups; they are formed at high $\mathrm{Cr}$ loadings, because they require the presence of a high density of $\mathrm{Cr}(\mathrm{II})$ sites along with the presence of small amounts of residual surface $\mathrm{OH}$ groups that enables a bimolecular $\mathrm{C}-\mathrm{H}$ activation at the $\mathrm{Cp}$ ligand to form bridging $\mathrm{Cr}$ (III) hydrides. The presence of a small fraction of adjacent surface hydroxyl groups is proposed to be important to split the dimeric $\mathrm{Cr}(\mathrm{III})$ hydrides into the monomeric species. The formation of $\mathrm{Cr}$ (III) hydrides, in situ via $\mathrm{C}-\mathrm{H}$ activation, is certainly a unique mode of activation for $\mathrm{Cr}$-based EP catalysts. These $\mathrm{Cr}(\mathrm{III})$ hydrides insert ethylene yielding monomeric $\mathrm{Cr}(\mathrm{III})$ alkyl species ( $=\mathrm{SiO}) \mathrm{CrCp}-\mathrm{C}_{2} \mathrm{H}_{5}$, which in turn can further insert and polymerize ethylene. Such structures inspired the preparation of an analog welldefined silica-supported system, namely $(\equiv \mathrm{SiO}) \mathrm{CrCp}\left[\mathrm{CH}\left(\mathrm{SiMe}_{3}\right)_{2}\right] \quad\left(\mathbf{4}-\mathrm{SiO}_{2}\right)$. Characterized by EPR spectroscopy, this material displays similar EPR signatures and EP activity as the UC catalysts, thus further supporting similar active site structures. Using hyperfine EPR spectroscopy, we also show that the well- 
defined $\mathrm{Cr}$ (III) surface alkyls perform ethylene polymerization via insertion into the $\mathrm{Cr}(\mathrm{III})-\mathrm{C}$ bond, thus supporting the analog proposition for the EP mechanism for the active species of the UC catalysts. This finding opens ways to design novel heterogeneous EP catalysts.

\section{Supporting Information}

The crystal structure have been deposited as CIF files in the Cambridge Structural database (CSD): 2149548 (2), $2149547\left(\left[\left(\mathrm{CpCrClCH}\left(\mathrm{SiMe}_{3}\right)_{2}\right)_{2}\right]\right)$.

\section{AUTHOR INFORMATION}

\section{Corresponding Author}

*E-mail: ccoperet@ethz.ch;

gunnar.jeschke@phys.chem.ethz.ch

\section{Author Contributions}

${ }^{\S}$ These authors contributed equally to the work

\section{Funding Sources}

D.T., A.N., and Y.K. are grateful to the Swiss National Foundation (SNF) for financial support of this work (grant no. 200021_169134,200020B_192050, and 200020B_192050 respectively).

Authors present address: P.-A. P.: Univ Lyon, Université Claude Bernard Lyon I, CNRS, INSA, CPE, UMR 5246, ICBMS, rue Victor Grignard, F-69622 Villeurbanne Cedex, France.

\section{ACKNOWLEDGMENT}

This manuscript is dedicated to the memory of Prof. Richard A. Andersen. The authors also thank Dr. Michael Wörle and Darryl Nater for assistance with crystallographic measurements; Dr. Zachariah J. Berkson for the SS NMR measurements; Prof. Keith Searles and Dr. Florian Allouche for scientific discussions. Dr. Romain Berthoud and Dr. John Severn are acknowledged for HT-SEC measurements.

\section{REFERENCES}

1. McDaniel, M. P., Chapter 3 - A Review of the Phillips Supported Chromium Catalyst and Its Commercial Use for Ethylene Polymerization. In Advances in Catalysis, Gates, B. C.; Knözinger, H., Eds. Academic Press: 2010; Vol. 53, pp 123-606.

2. Sailors, H. R.; Hogan, J. P., History of Polyolefins. J. Macromol. Sci. A 1981, 15 (7), 1377-1402.

3. Karapinka, G. Patent: US3709853A. 1973.

4. Karol, F. J.; Karapinka, G. L.; Wu, C.; Dow, A. W.; Johnson, R. N.; Carrick, W. L., Chromocene catalysts for ethylene polymerization: Scope of the polymerization. J. Polym. Sci. A Polym. Chem. 1972, 10 (9), 26212637.

5. $\quad$ Copéret, C.; Allouche, F.; Chan, K. W.; Conley, M. P.; Delley, M. F.; Fedorov, A.; Moroz, I. B.; Mougel, V.; Pucino, M.; Searles, K.; Yamamoto, K.; Zhizhko, P. A., Bridging the Gap between Industrial and Well-Defined Supported Catalysts. Angew. Chem. Int. Ed. 2018, 57 (22), 6398-6440. 
6. Copéret, C.; Comas-Vives, A.; Conley, M. P.; Estes, D. P.; Fedorov, A.; Mougel, V.; Nagae, H.; NúñezZarur, F.; Zhizhko, P. A., Surface Organometallic and Coordination Chemistry toward Single-Site Heterogeneous Catalysts: Strategies, Methods, Structures, and Activities. Chem. Rev. 2016, 116 (2), 323-421.

7. Zecchina, A.; Spoto, G.; Bordiga, S., Interaction of chromocene with the silica surface, and structure of the active species for ethene polymerization. Faraday Discuss. Chem. Soc. 1989, 87 (0), 149-160.

8. Schnellbach, M.; Köhler, F. H.; Blümel, J., The Union Carbide catalyst $\left(\mathrm{Cp}_{2} \mathrm{Cr}+\mathrm{SiO}_{2}\right)$, studied by solidstate NMR. J. Organomet. Chem. 1996, 520 (1), 227-230.

9. $\quad \mathrm{Fu}, \mathrm{S}$. L.; Lunsford, J. H., Chemistry of organochromium complexes on inorganic oxide supports. 1. Characterization of chromocene on silica catalysts. Langmuir 1990, 6 (12), 1774-1783.

10. Karol, F. J.; Wu, C., Chromocene-based catalysts for ethylene polymerization: Thermal removal of the cyclopentadienyl ligand. J. Polym. Sci. A Polym. Chem. 1974, 12 (7), 1549-1558.

11. Karol, F. J.; Wu, C.; Reichle, W. T.; Maraschin, N. J., Role of silanol groups in formation of supported chromocene catalysts. J. Catal. 1979, 60 (1), 68-76.

12. Fu, S. L.; Lunsford, J. H., Chemistry of organochromium complexes on inorganic oxide supports. 2. The interactions of carbon oxides with chromocene on silica catalysts. Langmuir 1990, 6 (12), 1784-1792.

13. Theopold, K. H.; Heintz, R. A.; Noh, S. K.; Thomas, B. J., Homogeneous Chromium Catalysts for Olefin Polymerization. In Homogeneous Transition Metal Catalyzed Reactions, American Chemical Society: 1992; Vol. 230, pp 591-602.

14. Ellis, P. J.; Joyner, R. W.; Maschmeyer, T.; Masters, A. F.; Niles, D. A.; Smith, A. K., An EXAFS investigation of chromocene on silica using empirical, semi-empirical and ab initio methods. J. Mol. Catal. A Chem. 1996, 111 (3), 297-305.

15. Allouche, F.; Chan, K. W.; Fedorov, A.; Andersen, R. A.; Copéret, C., Silica-Supported Pentamethylcyclopentadienyl Ytterbium(II) and Samarium(II) Sites: Ultrahigh Molecular Weight Polyethylene without Co-Catalyst. Angew. Chem. Int. Ed. 2018, 57 (13), 3431-3434.

16. Walter, M. D.; Burns, C. J.; Matsunaga, P. T.; Smith, M. E.; Andersen, R. A., Synthesis and Physical Properties of Pentamethylmanganocene, $\left(\mathrm{C}_{5} \mathrm{Me}_{5}\right) \mathrm{Mn}\left(\mathrm{C}_{5} \mathrm{H}_{5}\right)$, and the Inclusion Compounds $\left[\left(\mathrm{C}_{5} \mathrm{Me}_{5}\right)_{2} \mathrm{Yb}\right]_{2}\left[\left(\mathrm{C}_{5} \mathrm{H}_{5}\right)_{2} \mathrm{M}\right]$ (Where $\left.\mathrm{M}=\mathrm{V}, \mathrm{Cr}, \mathrm{Fe}, \mathrm{Co}\right)$. Organometallics 2016, 35 (20), 3488-3497.

17. Bunel, E. E.; Valle, L.; Manriquez, J. M., Pentamethylcyclopentadienyl acetylacetonate complexes of iron(II), cobalt(II), and nickel(II). Convenient synthetic entries to mono- $\eta^{5}-\mathrm{C}_{5} \mathrm{Me}_{5}$ derivatives. Organometallics 1985, 4 (9), 1680-1682.

18. Chisholm, M. H.; Cotton, F. A.; Extine, M. W.; Rideout, D. C., Dicyclopentadienyldi-tertbutoxydichromium. Preparation, properties, structure, and reactions with small unsaturated molecules. Inorg. Chem. 1979, 18 (1), 120-125.

19. Leoni, P.; Landi, A.; Pasquali, M., Isolation of the first neutral chromium formyl derivatives. J. Organomet. Chem. 1987, 321 (3), 365-369.

20. Gordon, C. P.; Shirase, S.; Yamamoto, K.; Andersen, R. A.; Eisenstein, O.; Copéret, C., NMR chemical shift analysis decodes olefin oligo- and polymerization activity of $\mathrm{d}^{0}$ group 4 metal complexes. Proc. Acad. Sci. U.S.A. 2018, 115 (26), E5867-E5876. 
21. Pollard, M.; Klimke, K.; Graf, R.; Spiess, H. W.; Wilhelm, M.; Sperber, O.; Piel, C.; Kaminsky, W., Observation of Chain Branching in Polyethylene in the Solid State and Melt via ${ }^{13} \mathrm{C}$ NMR Spectroscopy and Melt NMR Relaxation Time Measurements. Macromolecules 2004, 37 (3), 813-825.

22. Kitamaru, R.; Horii, F.; Murayama, K., Phase structure of lamellar crystalline polyethylene by solidstate high-resolution carbon-13 NMR detection of the crystalline-amorphous interphase. Macromolecules 1986, 19 (3), 636-643.

23. Blom, R.; Dahl, I. M.; Follestad, A.; Jens, K. J., Isomerisation on the $\mathrm{CrCp} / \mathrm{SiO}_{2}$ catalyst during polymerisation of ethylene: pressure dependence. J. Mol. Catal. A Chem. 1999, 138 (1), 97-102.

24. Peitz, S.; Peulecke, N.; Müller, B. H.; Spannenberg, A.; Rosenthal, U., Bis[ $\mu-N, N$ '-bis(2,6diisopropylphenyl)ethene-1,2-diamido]-1,4(n);1:2kN:N;3:4kN:N-bis(diethyl ether)-1кO,4kO-di- $\mu$-hydrido2:3kH:H-2,3-dichromium(II)-1,4-dilithium(I) pentane hemisolvate. Acta Cryst. E 2010, 66 (Pt 3), m296-m297.

25. Kreisel, K. A.; Yap, G. P. A.; Theopold, K. H., Organochromium Complexes Bearing Noninnocent Diimine Ligands. Eur. J. Inorg. Chem. 2012, 2012 (3), 520-529.

26. MacAdams, L. A.; Buffone, G. P.; Incarvito, C. D.; Golen, J. A.; Rheingold, A. L.; Theopold, K. H., A stable alkyl hydride of a first row transition metal. Chem. Commun. 2003, (10), 1164-1165.

27. Monillas, W. H.; Yap, G. P. A.; Theopold, K. H., A Tale of Two Isomers: A Stable Phenyl Hydride and a High-Spin (S=3) Benzene Complex of Chromium. Angew. Chem. Int. Ed. 2007, 46 (35), 6692-6694.

28. Filippou, A. C.; Schneider, S.; Schnakenburg, G., A Pair of Remarkably Stable Mononuclear Chromium(III) and Chromium(IV) Hydrides. Angew. Chem. Int. Ed. 2003, 42 (37), 4486-4489.

29. Sinnema, P.-J.; Shapiro, P. J.; Foo, D. M. J.; Twamley, B., Zwitterionic Ring-Borylated ansaChromocene Complexes. J. Am. Chem. Soc. 2002, 124 (37), 10996-10997.

30. Harlan, C. J.; Hascall, T.; Fujita, E.; Norton, J. R., The One-Electron Oxidation of an

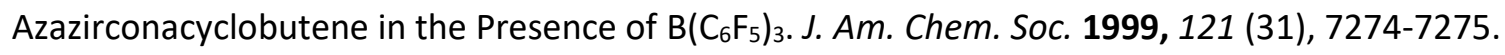

31. Choukroun, R.; Lorber, C.; Donnadieu, B., Zwitterionic, Ring-Borylated Vanadium(III) Complexes from $\left[\mathrm{Cp}_{2} \mathrm{VCO}\right]$ and $\mathrm{B}\left(\mathrm{C}_{6} \mathrm{~F}_{5}\right)_{3}$. Organometallics 2004, $23(6), 1434-1437$.

32. Bashkin, J.; Green, M. L. H.; Poveda, M. L.; Prout, K., Synthesis, structure, and reactions of a new dimer of molybdenocene, and related bi- and tri-nuclear compounds; molecular structures of $\left[\mathrm{H}\left(\eta^{5}\right.\right.$ $\left.\left.\mathrm{C}_{5} \mathrm{H}_{5}\right)_{2} \mathrm{Mo}\left(\mu-\sigma: \eta^{5}-\mathrm{C}_{5} \mathrm{H}_{4}\right) \mathrm{Mo}\left(\eta^{5}-\mathrm{C}_{5} \mathrm{H}_{5}\right)\right], \quad\left[\left(\eta^{5}-\mathrm{C}_{5} \mathrm{H}_{5}\right)(\mathrm{OC}) \mathrm{Mo}\left(\mu-\eta^{5}: \sigma-\mathrm{C}_{5} \mathrm{H}_{4}\right) \mathrm{Mo}(\mathrm{CO})_{2}\left(\eta^{5}-\mathrm{C}_{5} \mathrm{H}_{5}\right)\right], \quad$ and $\quad\left[\left\{\mathrm{Mo}\left(\eta^{5}-\right.\right.\right.$ $\left.\left.\left.\mathrm{C}_{5} \mathrm{H}_{5}\right)\right\}_{2}\left(\mu-\eta^{5}-\mathrm{C}_{5} \mathrm{H}_{4}-\eta^{5}-\mathrm{C}_{5} \mathrm{H}_{4}\right) \mathrm{H}_{3}\right] \mathrm{PF}_{6}$. J. Chem. Soc., Dalton Trans. 1982, (12), 2485-2494.

33. Ashuiev, A.; Allouche, F.; Wili, N.; Searles, K.; Klose, D.; Copéret, C.; Jeschke, G., Molecular and supported Ti(iii)-alkyls: efficient ethylene polymerization driven by the $\pi$-character of metal-carbon bonds and back donation from a singly occupied molecular orbital. Chem. Sci. 2021, 12 (2), 780-792.

34. Heintz, R. A.; Leelasubcharoen, S.; Liable-Sands, L. M.; Rheingold, A. L.; Theopold, K. H., Structure and Reactivity of Trimethylsilylmethyl Complexes of Chromium, Including the 13-Electron Alkyl $\mathrm{Cp} * \mathrm{Cr}\left(\mathrm{CH}_{2} \mathrm{SiMe}_{3}\right)_{2}$. Organometallics 1998, 17 (25), 5477-5485.

35. White, P. A.; Calabrese, J.; Theopold, K. H., $\alpha$-Olefin Polymerization with Ether-Coordinated Chromium(III) Alkyls. Organometallics 1996, 15 (26), 5473-5475.

36. Morra, E.; Martino, G. A.; Piovano, A.; Barzan, C.; Groppo, E.; Chiesa, M., In Situ X- and Q-Band EPR Investigation of Ethylene Polymerization on $\mathrm{Cr} / \mathrm{SiO}_{2}$ Phillips Catalyst. J. Phys. Chem. C 2018, 122 (37), 2153121536. 
37. Brown, C.; Lita, A.; Tao, Y.; Peek, N.; Crosswhite, M.; Mileham, M.; Krzystek, J.; Achey, R.; Fu, R.; Bindra, J. K.; Polinski, M.; Wang, Y.; van de Burgt, L. J.; Jeffcoat, D.; Profeta, S.; Stiegman, A. E.; Scott, S. L., Mechanism of Initiation in the Phillips Ethylene Polymerization Catalyst: Ethylene Activation by $\mathrm{Cr}(\mathrm{II})$ and the Structure of the Resulting Active Site. ACS Catal. 2017, 7 (11), 7442-7455.

38. Delley, M. F.; Núñez-Zarur, F.; Conley, M. P.; Comas-Vives, A.; Siddiqi, G.; Norsic, S.; Monteil, V.; Safonova, O. V.; Copéret, C., Proton transfers are key elementary steps in ethylene polymerization on isolated chromium(III) silicates. Proc. Acad. Sci. U.S.A. 2014, 111 (32), 11624-11629.

39. While both low-spin and high-spin Cr species are observ-able by CW EPR (see Fig. S13 as an example), pulse EPR investigations of $\mathrm{Cr}$ high-spin ( $\mathrm{S}>1 / 2$ ) species, where zero-field splitting (ZFS) is often the dominant magnetic interaction, is often limited due to short T2 relaxation times, even at temperatures of around 2-20 K (see Chabbra, S.; Smith, D. M.; Bode, B. E., Isolation of EPR spectra and estimation of spin-states in twocomponent mixtures of paramagnets. Dalton Transactions 2018, 47 (31), 10473-10479; and Hirscher, N. A.; Arnett, C. H.; Oyala, P. H.; Agapie, T., Characterization of Cr-Hydrocarbyl Species via Pulse EPR in the Study of Ethylene Tetramerization Catalysis. Organometallics 2020, 39 (24), 4420-4429). On the other hand, both high-spin (HS, $S=3 / 2$ ) and low-spin (LS, $S=1 / 2$ ) states were previously observed for $\mathrm{Cr}(\mathrm{III})$ alkyl complexes, depending on their ligand surrounding (ref 29). Also, grafting of the $\mathrm{Cr}\left(\mathrm{N}\left(\mathrm{SiMe}_{3}\right)_{2}\right)_{3}$ complex on silica, followed by thermal treatment at $400^{\circ} \mathrm{C}$, provided $\mathrm{Cr}$ (III) species that are in a LS state, so that pulse EPR measurements were possible already at $110 \mathrm{~K} .($ ref 30$)$

40. Höfer, P.; Grupp, A.; Nebenführ, H.; Mehring, M., Hyperfine sublevel correlation (hyscore) spectroscopy: a 2D ESR investigation of the squaric acid radical. Chem. Phys. Lett. 1986, 132 (3), 279-282.

41. Allouche, F.; Klose, D.; Gordon, C. P.; Ashuiev, A.; Wörle, M.; Kalendra, V.; Mougel, V.; Copéret, C.; Jeschke, G., Low-Coordinated Titanium(III) Alkyl-Molecular and Surface-Complexes: Detailed Structure from Advanced EPR Spectroscopy. Angew. Chem. Int. Ed. 2018, 57 (44), 14533-14537. 